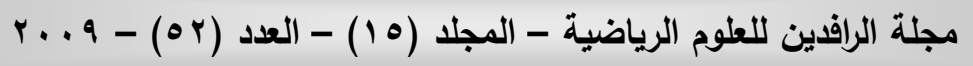

اثر استخدام أسلويي جدولة التمرين العشوائي والتمرين المتسلسل في تطوير الأداء المهاري للرجل غير المفضلة للاعبي كرة القدم

م.د نوفل فاضل رشيد

جامعة الموصل / كلية التربية الرياضية

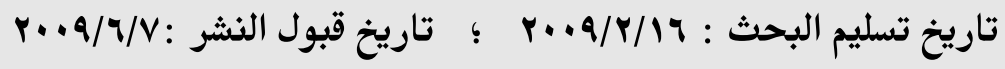

الملخص

- يهدف البحث إلى :

1. الكشف عن اثر استخدام أسلوبي جدولة التمرين العشوائي والتمرين المتسلسل في تطوير

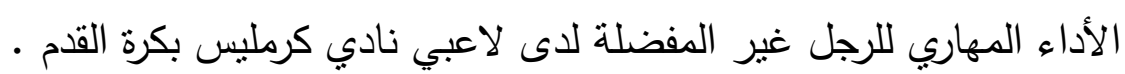

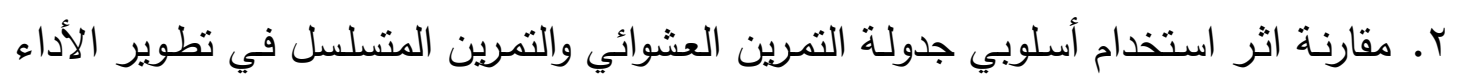

المهاري للرجل غير المفضلة للاعبي نادي كرمليس بكرة القدم في الاختبار البعدي .

- تم استخدام المنهج التجريبي لملائمته وطبيعة مشكلة البحث ، تكونت عينة البحث من لاعبي

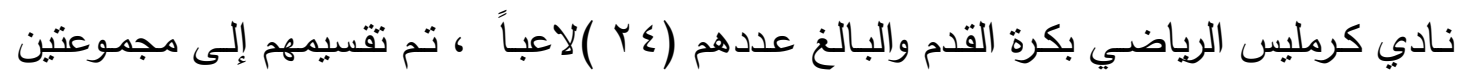

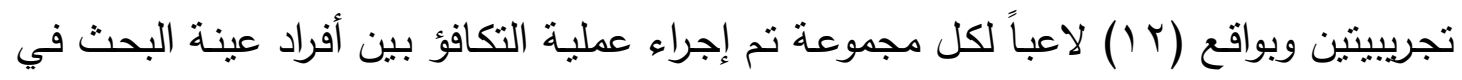

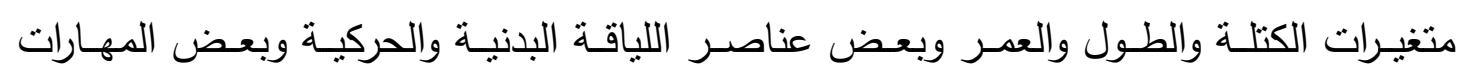

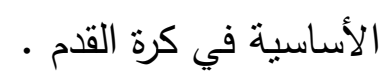
- استغرق تتفيذ البرنامج خمسة أسـابيع وزعت خلالها الوحدات التدريبيـة وبواقع (r) وحدات

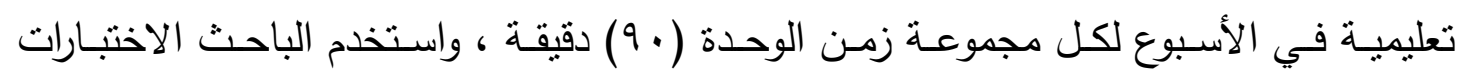
والمقاييس والمقابلة كوسيلة لجمع المعلومات.

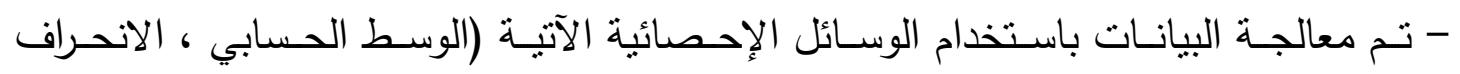

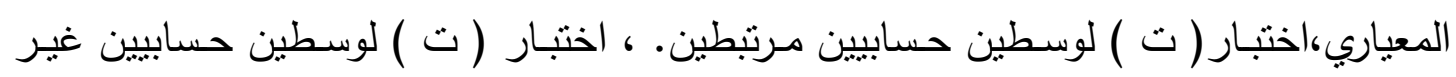
مرتبطين) - واستنتج الباحث ما يأني : مرين : ا ـ كان لأسلوبي جدولة التمرين (العشوائي ، والمنسلسل ) تأثنير ايجابي في تطوير الأداء المهاري للرجل غير المفضلة لدى لاعبي نادي كرمليس بكرة القدم.

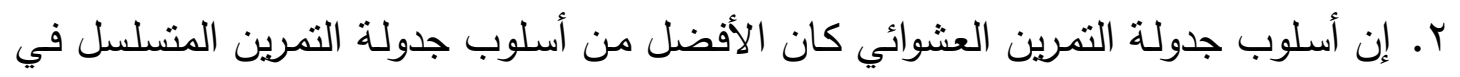
تطوير الأداء المهاري للرجل غير المفضلة للاعبي كرة القدم . 


\section{ABSTRACT \\ The impact of using Blocked and Random scheduling \\ practice styles in developing skill performance for the \\ undominant leg for football players}

Lecturer.Dr. Nawfel. F. Rashid

Mosul university / college of physical education

1. To explore the impact of using blocked and Random scheduling practice styles in developing the skill performance for the undominant leg for football players.

2. To compare in post-test the impact of using blocked and Random scheduling practice styles in developing the skill performance for the undominant leg for football players

- Experimental method was used to suit the nature of the study, sample of the study consisted of (24) players, which they represented the Karamles sport club players, which divided into two equal empirical groups, each group consisted of (12) players for each group , equivalent and homogeneous was done for the sample in variables of ( mass, length, age , some of motor and physical elements, some of basic skills in football.

- Program period was (5) weeks, (3) learning units in a week for each group, time for each unit was (90) minutes. The research used the tests and measurements as a tools for the research in pre-post skills tests.

- Data was treated statistically by using the \{ Arithmetic mean , standard deviation, (T) test for the paired and unpaired samples $\}$.

The researcher concluded the following :-

1. The blocked and Random scheduling practice styles have normal effect in developing the skill performance for the undominant leg for football players hn Karamles club .

2. The Random scheduling practice styles was better than the blocked scheduling practice styles in developing the skill performance for the undominant leg for football players Karamles club. 


\section{1 - التعريف بالبحث :}

\section{1-1 المقدمة وأهمية البحث :}

يعد التطور المستمر في عمليتي التعليم والتدريب الرياضي من سمات عصرنا الحالي

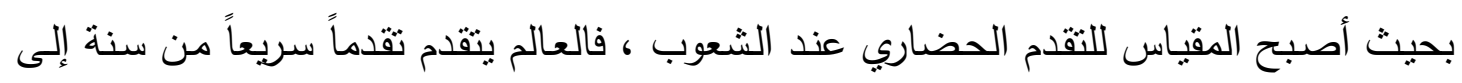

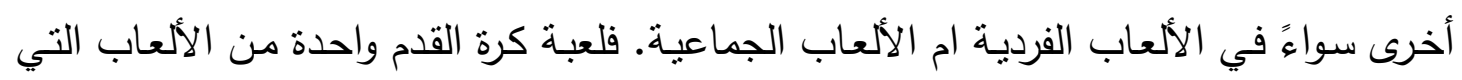
تطورت تطوراً كبيراً منذ نشوءها.

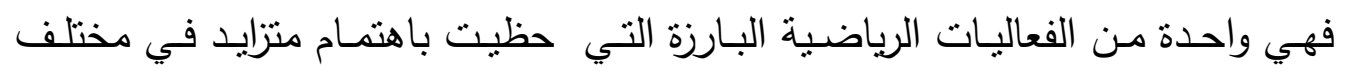

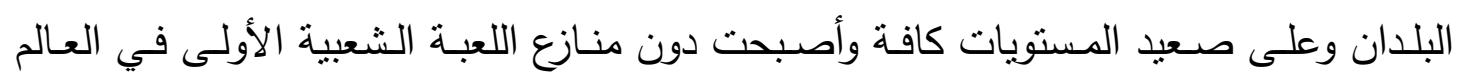
يمارسها الجميع في أي وقت وأي مكان، وبسبب هذه الثعبية الكبيرة لها انصب اهتمام الباحثين إلى تطويرها من خلال رفع مستويات اللاعبين من الناحية البدنية والخططية والنفسية، فضلاً

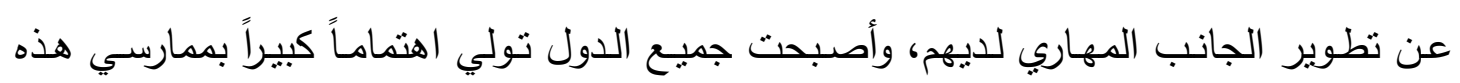

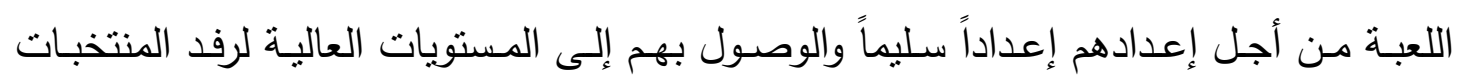

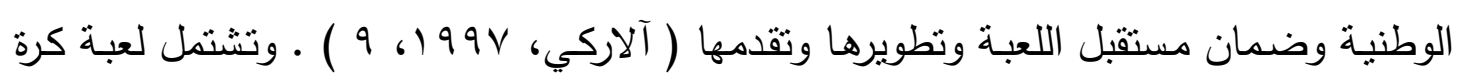
القدم على مهارات كثيرة ومنتوعة وتحتاج هذه المهارات إلى التعليم المبكر والمستمر لكي يتعلمها لإنها اللاعب ويتقنها وتتباين درجة تعلم هذه المهارات من لاعب إلى أخر تبعاً للفروقات الفردية ولثية

$$
\text { بينهما كالفروقات الجسمية والنفسية والتربوية (الحسيني، ع . . r ، r ) ). }
$$

إن التدريب الرياضـي هدفه الأسـاس الوصـول باللاعب إلى أعلى المستويات البدنيـة

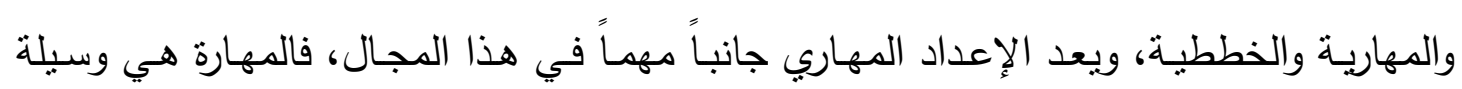

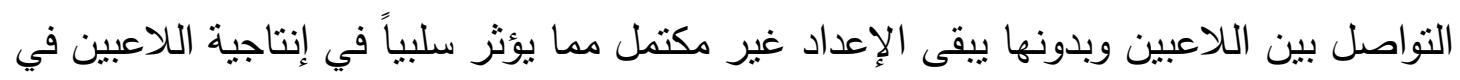

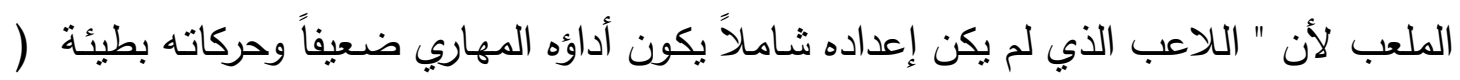

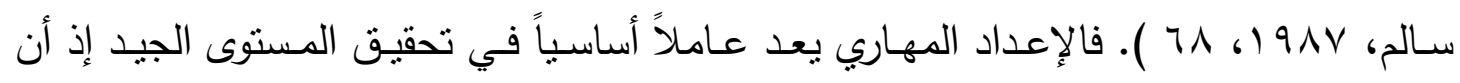

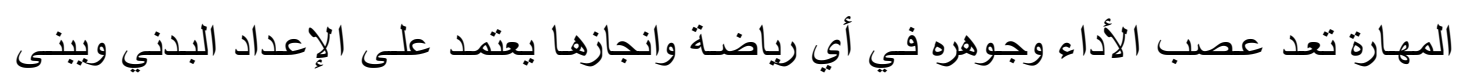

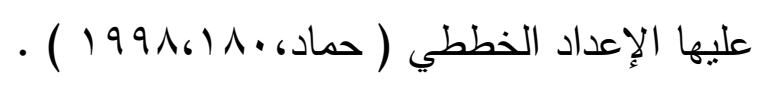

ويثير ( المتيوتي، نقلاً عن Adams\&Victors) إلى ازدياد اهتمام الباحثين والمدربين

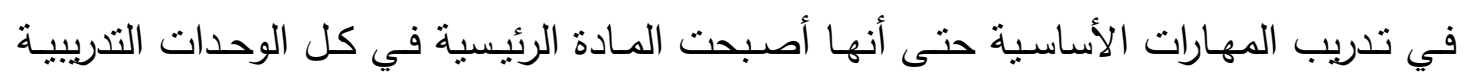

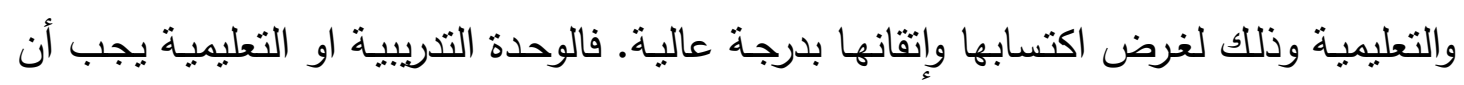
تحتوي على تمارين هدفها نطوير الجانب المهاري ولكن يجب أن توضع بأسلوب علمي يضمن ونه

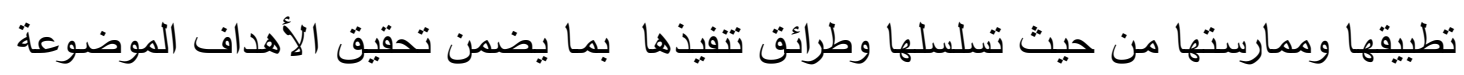


مـن أجلها، ومـن هنـا كـان لابـد مـن مراقبـة أداء اللاعب في الوحدات التدريبيـة بمـا يضمن استخدامه كلتا القدمين في أداء التمارين من أجل إيجاد لاعب متكامل قادر علـ على استخدام

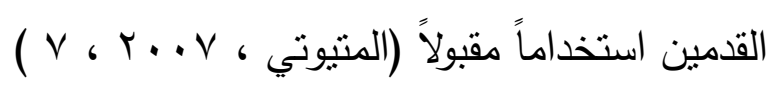

لذا ظهرت العديد من الوسـائل الجديدة والحديثة التي يمكن من خلالها دفع العملية التعليمية والتنريبيـة التي يمثل كل منها مضموناً ومحتويً تطبيقياً لنظريـة من نظريـات التعلم الحركي الكثيرة والمتتوعة. ( 175 ، 1982 ، Schmidt ).

وجدولة الممارسة واحدة من هذه الوسائل التي تسهم بشكل إيجابي في تحقيق التتوع في

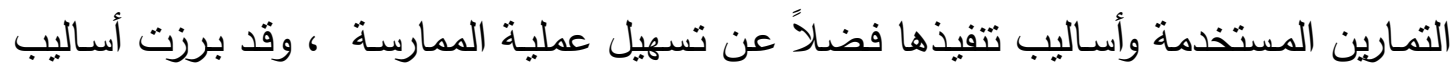
تعليمية جديدة تطبق داخل التمرين لغرض تطوير وتحسين الأداء ، ومن ضمنها أسلوب التمرين

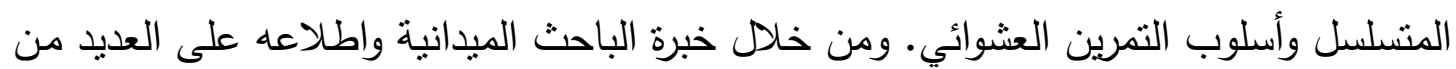

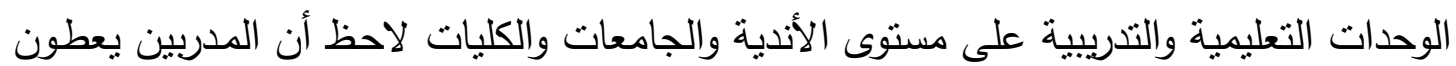
للاعب الحرية في استخدام القدم التي يراها مناسبة له في الأداء، مما جعل اللاعبين يطورون قدماً على حساب القدم الأخرى، وهذا ما كان له الأثر السلبي في إعداد اللاعب مهارياً. ومن هنـا برزت أهيـة البحث في استخدام أسلوبين من جدولـة التمرين وهما أسلوب التمرين العشوائي وأسلوب التمرين المتسلسل والتعرف على أفضل أسلوب من هذين الأسلوبين في تطوير الأداء المهاري للرجل غير المفضلة للاعبي كرة القدم .

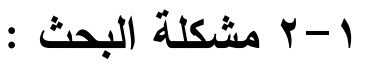

حسب خبرة الباحث كلاعب ومدرب في بعض الكليات والفرق الرياضية على مسنوى المحافظــة وكمششاهد لكثيـر مـن المباريـات للفرق المحليـة والعالميـة لاحظظ أن أكثر اللاعبـين

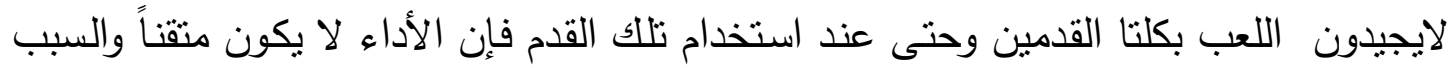
في ذلك عدم اهتمام المدربين في تطوير هذه القدم، أو أن بعض اللاعبين يفضل استخدام القدم

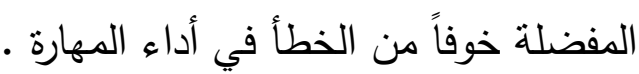
ومن هنا برزت مشكلة البحث في الإجابة عن النساؤل الأتي : هل أن أسلوب التمرين العشوائي وأسلوب التمرين المتسلسل يعملان على تطوير الأداء المهاري للرجل غير المفضلة للاعبي كرة القدم ؟ وأيهما سيكون الأكثر نطويراً ؟ 
1-ب-1 الكشف عن اثر اسـتخدام أسـلوبي جدولـة التمـرين العشوائي والتمـرين المتسلسل في تطوير الأداء المهاري للرجل غير المفضلة لاى لاعبي نادي كرمليس بكرة القدم .

ا-r-r-r مقارنة اثر استخدام أسلوبي جدولة التمرين العشوائي والتمرين المتسلسل في تطوير الأداء المهاري للرجل غير المفضلة للاعبي كرة القدم في الاختبار البعدي •

:

1-ـ - وجـود فروق ذات دلالـة إحصائية بـين نتـائج الاختبـارات القبليـة والبعديـة في الأداء المهـاري للرجـل غيـر المفضلة للاعبـي كـرة القـدم ولمــلحة الاختبـارات البعديـة وللمجموعتين التجريبيتين.

1- - - الاتوجد فروق ذات دلالــة إحصائية بـين نتـائج الاختبـارات البعديـة بـين المجمـوعتين التجريبيتين في الأداء المهاري للرجل غير المفضلة للاعبي كرة القدم.

\section{: 1 - 1 مجالات البحث:}

1-0-1 المجال البشري : لاعبي نادي كرمليس الرياضي بكرة القدم للموسم الرياضي ^ . . ץ. r. . 9

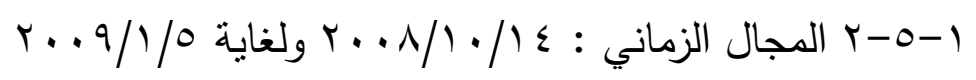

$$
\begin{aligned}
& \text { 1-0-r المجال المكاني : ملعب نادي كرمليس الرياضي . } \\
& \text { 1- - المصطلحات الواردة في البحث : } \\
& \text { 1- - أسلوب التمرين العشوائي : }
\end{aligned}
$$

عرفه (خيون) بأنه “ قيام المتعلم بالتدريب على أكثر من مهارة في الوحدة التعليمية الواحدة “،

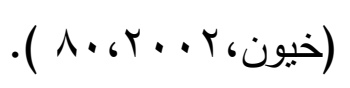

ويعرفه ( محجوب ) بأنه “ عرض المهام التعليمية عشوائياً على المتعلم بحيث يكون التمرين على المهارات أو الواجبات الحركية متداخلاً ، ويستطيع المتعلم أن يدور بين هذه المهارات بالنتائج دون التمرن على المهارة نفسها في محاولتين متتاليتين ،"،

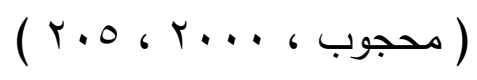


يعرفه (Schmidt ) بأنه “ السلسلة المتعاقبة من التمرين التي يكون ممارسة تمريناتها

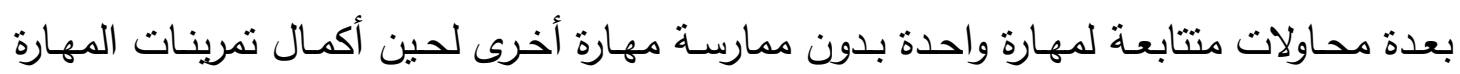
الأولى " (Schmidt , 1991,274).

وعرفها ( الدليمي ) بأنه ” الأسلوب الذي بعتمد على تعلم المهارة بشكل متسلسل وصولاً

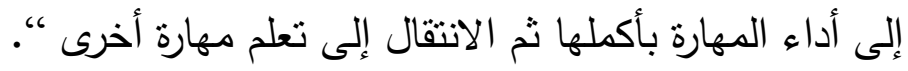

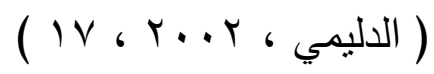

1- 1- الرجل غير المفضلة ( الرجل غير المفضلة ) : عرفها ( المنتوتي ) بأنها " هي الرجل الساندة والمساعدة، والتي تكون في أغلب

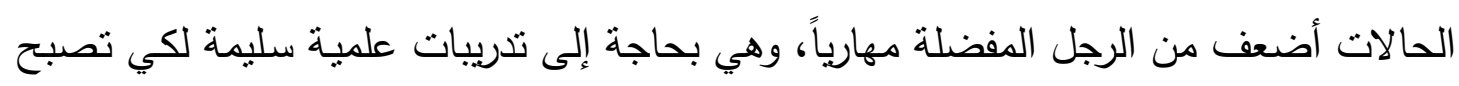
فعالياتها وقوتها قريبة من درجة فعالية الرجل المفضلة ".

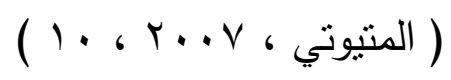

r - الإطار النظري والدراسات السابقة :-

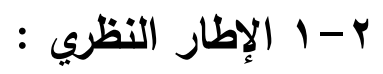
r-1 - أسلوب التمرين العشوائي : يعرفه ( Herbert \& Solman ) بأنه “ تبادل محاولات التمرين على مهارة معينة

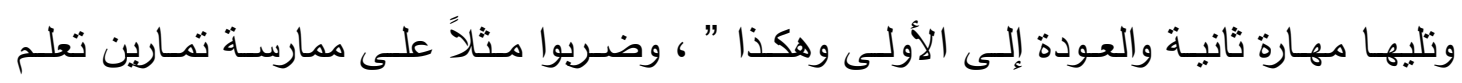

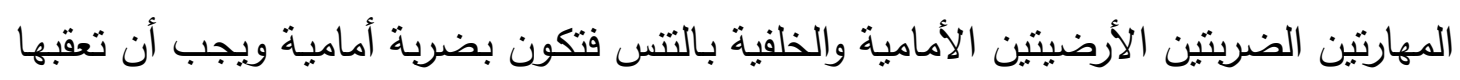

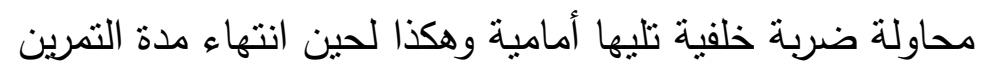

.( Herbert\& Solman 1996, 52-58)

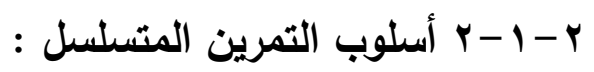

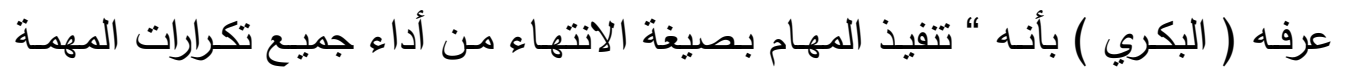

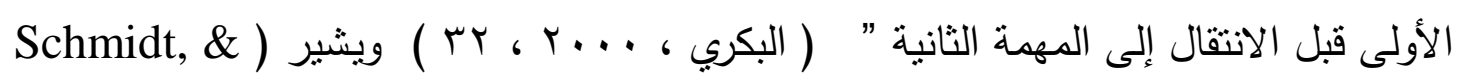

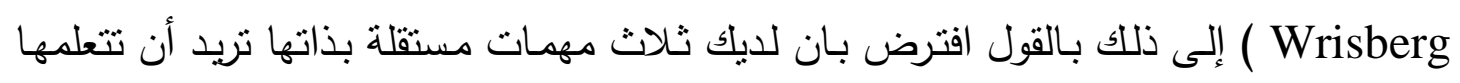

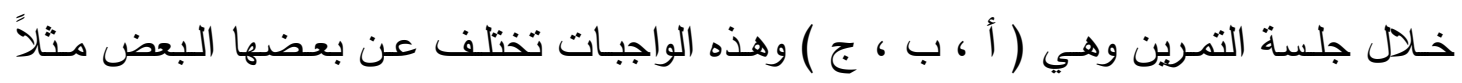
( ثلاث العاب مختلفة في الجمناستلك أو ثلاث مهارات مختلفة في كرة القدم أو ثلاثثة أعمال

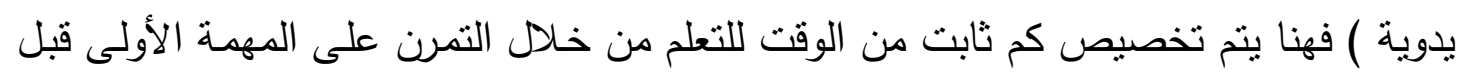

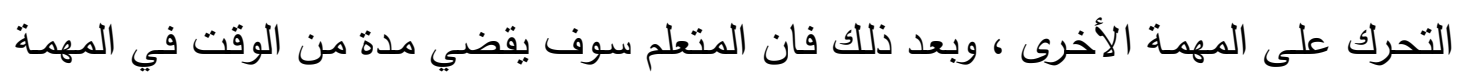

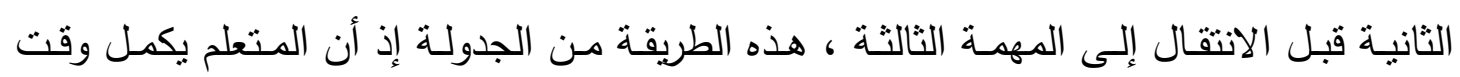


التمرين في قضاء مهمة واحدة قبل البدء بالتمرين على المهمة الأخرى يدعى بالتمرين المتسلسل ( Schmidt, \& Wrisberg 2000,233 )

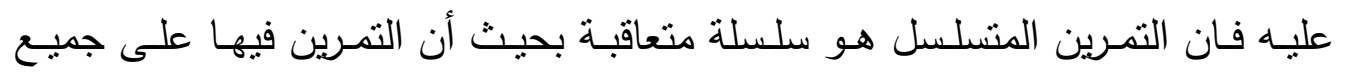

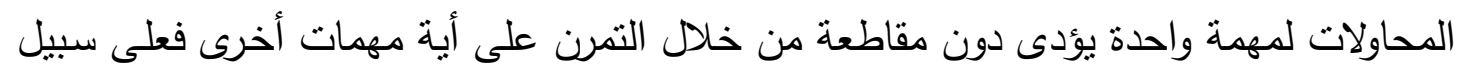

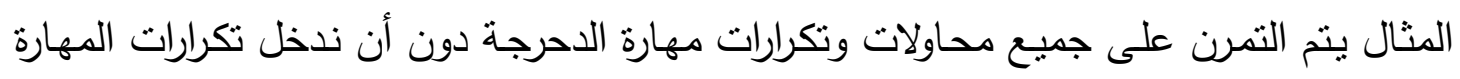
الثانية مثنا مهارة التمريرة وهكذا لحين انتهاء مدة التمرين .

في حين أن التمرين العشوائي يحدث من ناحية الأخرى إذ لايتم تكرار نفس المهـة

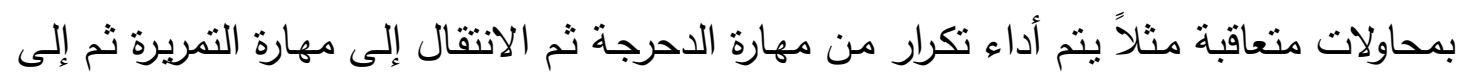

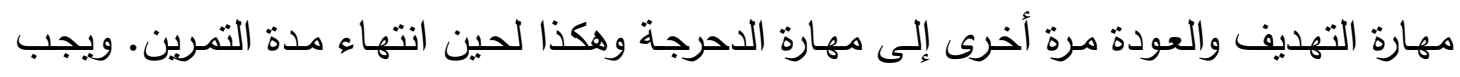

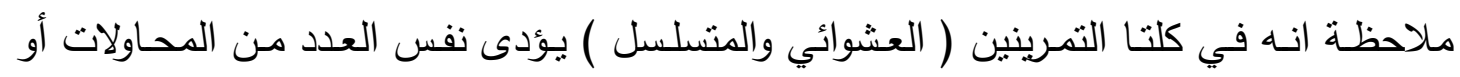

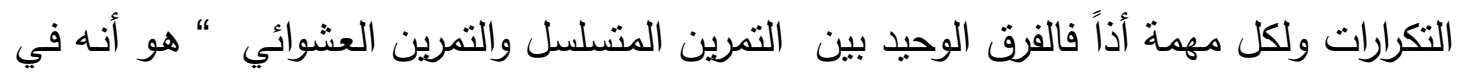

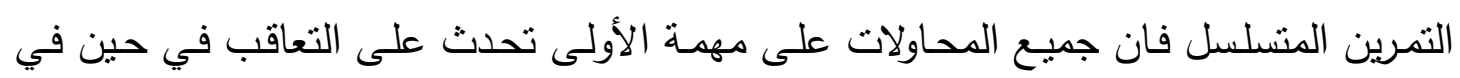

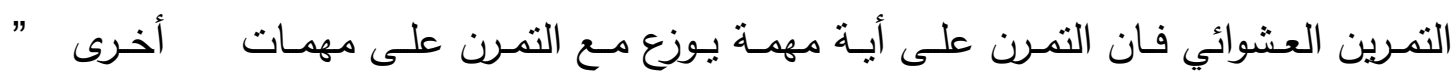

.( Schmidt \& Lee , 1999 , 271)

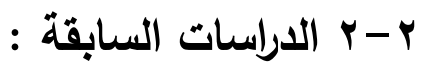

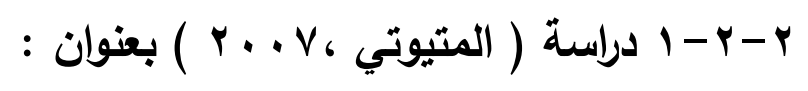

" أثر تمارين مهاريـة بأسلوب المنافسات على تطوير بعض المهارات الأساسية للرجل غير المفضلة للاعبين الناشئين بكرة القدم "

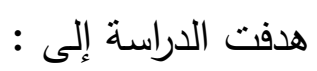
الكثف عن أثر الوحدات التدريبية الخاصـة بأسلوبي التنافس الزوجي والفردي في تطوير الأداء المهاري للرجل غير المفضلة بكرة القدم القرح الكثف عن دلالة الفروق بين الاختبارات البعدية للمجموعتين التجريبيتين.

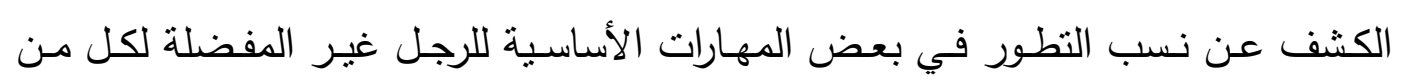
المجموعنين التجريبيتين. - أجريت الدراسة على عينة من لاعبي منتخب ناشئة محافظة نينوى بكرة القدم وكان عددهم

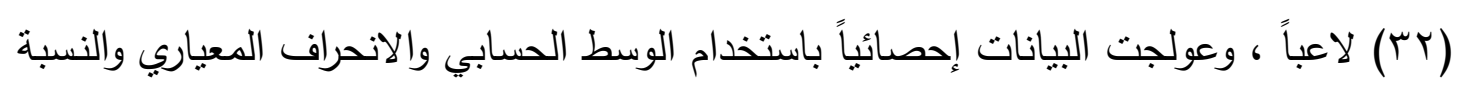
المئوية والجذر التربيعي لمعامل الثبات والارتباط البسيط بيرسون واختبار (ت) لمتوسطين غير إناسئ مرتبطين ومرتبطين لعينتين متساويتين وقانون نسبة التطور • 
- وتوصل الباحث إلى الاستتناجات الآتية: ا. إن الوحدات التدريبية الخاصة إذا ما خطط لها تخطيطاً جيداً فإنها تعمل على تطوير الرجل الرهل غبر المفضلة. r. أن نسب تطوير المهارات الأساسية متفاوتة ما بين مهارة وأخرى. r.إن أسلوب التتافس الزوجي تكون نسبة تطوير المهارات الأساسية فيه أكبر من نسبة نطوير

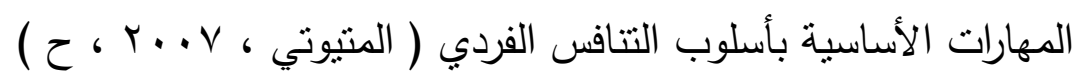

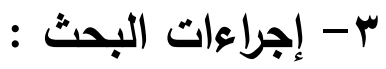

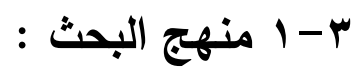
استخدم المنهج التجريبي لملائمته ومشكلة البحث.

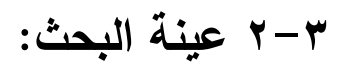

تكونت عينة البحث من (rV) لاعباً يمثلون نادي كرمليس الرياضي بكرة القدم ، وقد تم

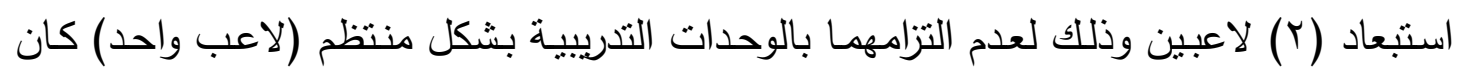

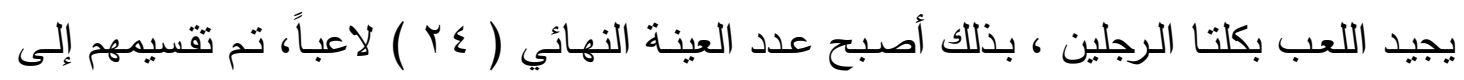
مجموعتين تجريبيتين وبواقع ( Y ) لاعباً لكل مجموعة. r-r ا التصميم التجريبي : n تم اسـتخدام التصميم التجريبـي الذي يطلاق عليهـ أسـم (تصميم الهجموعـات المتكافئة العشوائية الاختبار ذات الملاحظة القبلية والبعدية )

\begin{tabular}{|c|c|c|c|}
\hline الاختبار البعدي & المتغير ات & الاختبار القبلي & المجامبع \\
\hline خ - ب ت 1 & م -1 & خ -ق ت 1 & 10 \\
\hline خ - ب ت & r. . & خ -ق ت ب & ت تr \\
\hline
\end{tabular}

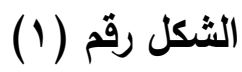

يوضح التصميم التجريبي للبحث

(علاوي ، وراتب ، 1999 ، كTM ).

المجموعة التجريبية الأولى .

1 خ.ق ت ال الاختبار القبلي للمجموعة التجريبية الأولى . 


$$
\begin{aligned}
& \text { م · 1 المتغير المستقل الأول (أسلوب التمرين العشوائي) } \\
& \text { خ · ب ت الاختبار البعدي للمجموعة التجريبية الأولى • }
\end{aligned}
$$

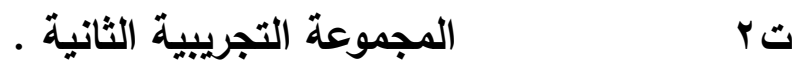

$$
\begin{aligned}
& \text { خ • ت ت ب الاختبار القبلي للمجموعة التجريبية الثانية . } \\
& \text { م · r المتغير المستقل الثاني (أسلوب التمرين المتسلسل ) • } \\
& \text { خ · ب ت ب الاختبار البعدي للمجموعة التجريبية الثانية . } \\
& \text { r- } \\
& \text { - المقابلة - }
\end{aligned}
$$

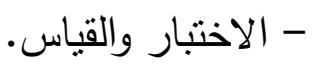

ب- - 1 تحديد عناصر اللياقة البدنية والحركية والمهارات الأساسية في كرة القدم واختباراتها

تم استخدام مجموعـة من العناصـر البدنيـة والحركيـة وبعض من المهارات الأساسية والاختبارات الخاصـة بهما والتي سبق وان تم استخدامها من قبل باحثين في كرة القدم ، وهذه الاختبارات تتمتع بأسس علمية من صدق وثبات وموضوعية ، والملحقان ( او r ) يوضحان العناصر البدنية والمهارات الأساسية والاختبارات المستخدمة في البحث.

\section{ب-ه تكافؤ مجموعتي البحث :}

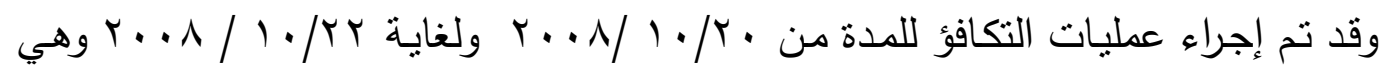

تعد بمثابة قياس قبلي للمجموعتين التجربيتين ، وشملت عملية التكافؤ المتغيرات الآتية : -

r-ه - التكافؤ في متغيرات (الكتلة والعمر والطول)

تم إجراء عملية التكافؤ بين أفراد عينة البحث في متغيرات الكتلة والعمر والطول ، وكما

مبين في الجدول رقم (1)

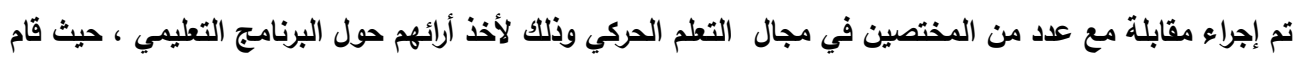

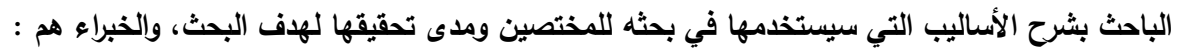

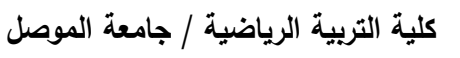
- أ أد عامر محمد سعودي

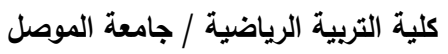

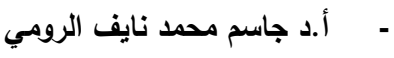
كلية التربية الرياضية / جامعة الموصل الترية التربة الموصل

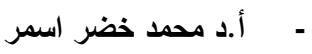

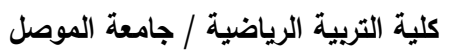

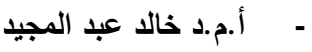
كلية التربية الرياضية / جامعة الموصل الرياضل جامعة الموصل

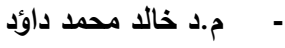
كلية التربية الرياضية / جامعة الموصل الرياضية المعل

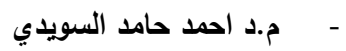




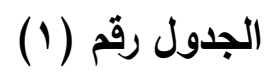

يبين الأوساط الحسابية والانحرافات المعيارية وقيمة (ت) المحسوية لعينة البحث في متغيرات (الكتلة والعمر والطول)

\begin{tabular}{|c|c|c|c|c|c|}
\hline \multirow{2}{*}{ قامة (ت) } & \multicolumn{2}{|c|}{ (أسلوب التمرين التجرينية الثتانية } & \multicolumn{2}{|c|}{ (أسلوب التمرين التجريبية الأولى ائيلى } & \multirow[t]{2}{*}{ المتغيرات } \\
\hline & $\varepsilon \pm$ & س- & $\varepsilon \pm$ & س- & \\
\hline$\cdot, 0 \leq V$ & 0,110 & $\neg \varepsilon, \wedge) \wedge$ & $0, \vee \wedge 0$ & $7 \pi, 0 \leqslant 7$ & الكتلة / كفم \\
\hline גז" & $r, r \wedge 0$ & $r r, q . q$ & $r, v) \vee$ & $r \cdot, V Y V$ & العمر / سنة \\
\hline$\cdot, \vee \wedge \varepsilon$ & $r, \Lambda . \tau$ & $177,9.9$ & $V, 1 Y \varepsilon$ & $|7 \wedge, \wedge| \wedge$ & الطول / سم \\
\hline
\end{tabular}

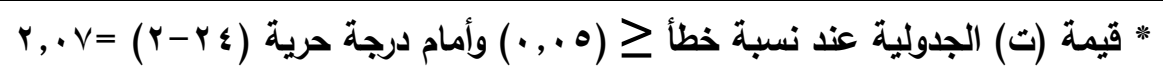
يتبين من الجدول رقم ( () وجود فروق غير معنوية بين أفراد المجموعتين التجريبيتين

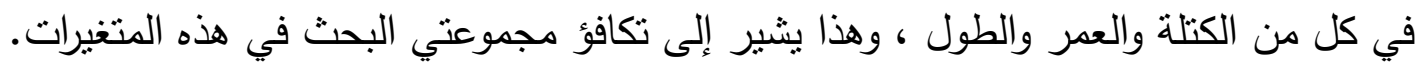
r-r r - تكافؤ مجموعتي البحث في بعض عناصر اللياقة البذنية والحركية في كرة القام :

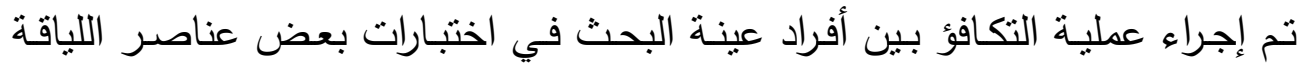

البدنية والحركية ، وكما مبين في الجدول رقم (r)

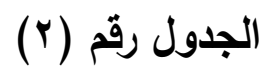

يبين الأوساط الحسابية والانحرافات المعيارية وقيمة (ت) المحسوية لعينة البحث في اختبارات العناصر البدنية وإلحركية المختارة

\begin{tabular}{|c|c|c|c|c|c|}
\hline \multirow{2}{*}{ قيمة (ت) } & \multicolumn{2}{|c|}{ (السلوبو التمرين التجريبية الثانية } & \multicolumn{2}{|c|}{ (أسلوب التمرين التشويبية الأولى } & \\
\hline & $\varepsilon \pm$ & س - & $\varepsilon \pm$ & س- & \\
\hline $1, \cdot v_{1}$ & $v,(q)$ & 7r, & T, TYK & חוצידו & القوة الانفجارية للرجلين/ سم \\
\hline $1, v \cdot 9$ & $\cdot, r \wedge r$ & $q, Y \vee \leqslant$ & •, & $\Lambda, q \vee 0$ & الرشاقة / ثانية \\
\hline., $01 \mathrm{~V}$ & מצו & $1,9 \cdot 9$ & $7, Y \leq 7$ & $r, Y V Y$ & المرونة / سم \\
\hline
\end{tabular}

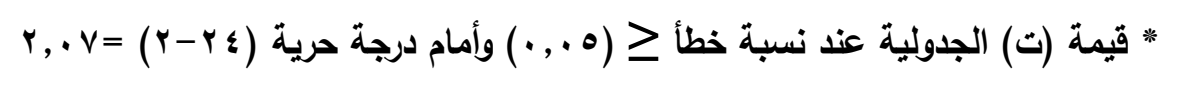

يتبين من الجدول رقم (r) وجود فروق غير معنوية بين أفراد المجموعتين التجريبيتين في اختبارات عناصر اللياقة البدنية والحركية ،وهذا يشير إلى تكافؤ مجموعتي البحث في هذوف لهنه 
r-ه - ب تكافؤ مجموعتي البحث في بعض المهارات الأساسية :

تم إجراء عملية التكافؤ بين أفراد عينة البحث في اختبارات بعض المهارات الأساسية المختارة

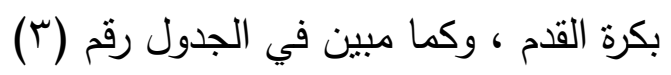

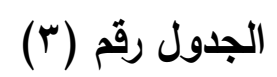

يبين الأوساط الحسابية والانحرافات المعيارية وقيمة (ت) المحسوية لعينة البحث في الاختبارات المهارية المختارة

\begin{tabular}{|c|c|c|c|c|c|}
\hline \multirow{2}{*}{ قيمة (ت) } & \multicolumn{2}{|c|}{ (أسلوب التمرين المتسلسلة التجريبية الثانية } & \multicolumn{2}{|c|}{ (أسلوب التمرين العشوعة التجريبة الأولى } & \multirow{2}{*}{ لعناصر البدنيالة الإحصائية } \\
\hline & $\varepsilon \pm$ & س- & $\varepsilon \pm$ & س - س & \\
\hline $1, \leqslant 00$ & $\cdot, \wedge \cdot 9$ & צוד & $\cdot, 9 \leq r$ & $\varepsilon, .9$. & الإخماد/درجة \\
\hline $1, \ldots r$ & سזr, • & $I V, 7 \wedge V$ & $\cdot, r q$. & $1 V, 0 \vee \varepsilon$ & الاحرجة/ ثانية \\
\hline$\cdot, 091$ & 1, rvo & $9,9 \cdot 9$ & $r, 11$. & سצr, • & التمريرة القصيرة/درجة \\
\hline$\cdot, 1 \leq 9$ & $1, r \wedge T$ & 0,7 ב 0 & 1,000 & $0, V Y V M$ & التهديف القريب/ درجة \\
\hline
\end{tabular}

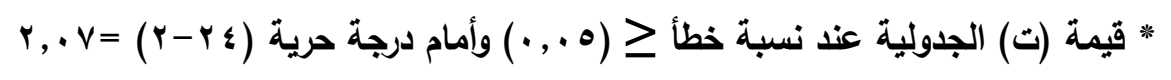

يتبين من الجدول رقم (r) وجود فروق غير معنوية بين أفراد المجموعتين التجريبيتين

في الاختبارات المهارية المختارة ،وهذا يشير إلى تكافؤ مجموعتي البحث في هذه فئ المهارات.

\section{ب-ף تصميم الوحدات التعليمية والتدريبية الخاصة:}

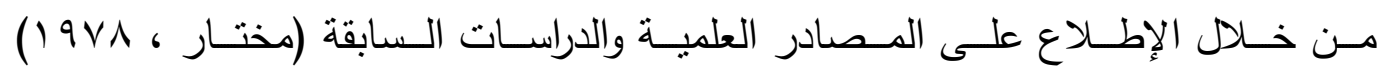

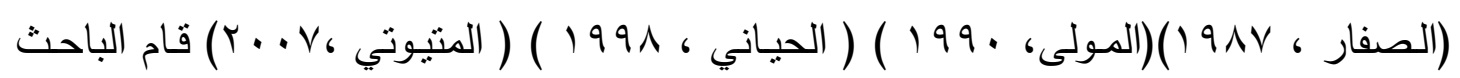
بإعداد وحدات تدريبية خاصة بأسلوب التمرين العشوائي وأسلوب التمرين المتسلسل وراعى في التي

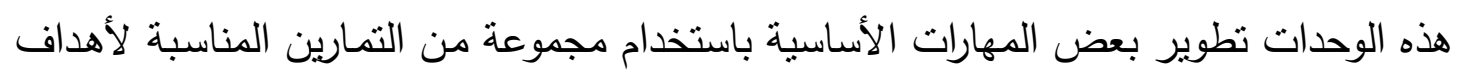

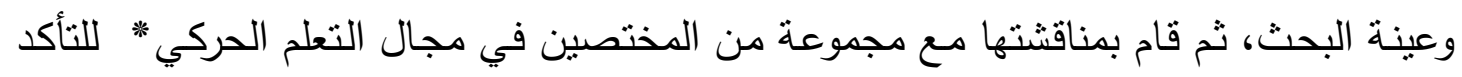


من مدى صلاحية هذين البرنامجين وطريقة تتفيذها وتعديل ما يرونه مناسباً. والملحقان ( آو ع ) يوضحان نموذجين للوحدات التدريبية المقترحة. r-v الخطة الزمنية للبرنامجين التدريبيين:

تضمنت البرامج التدريبية (•r) وحدة تدريبيـة للأسـاليب المستخدمة في البحث وموزعـة على مجموعتي البحث وبواقع (10 ) وحدة تدريبية لكل مجموعة، وقد استغرق تتفيذ البرنامج (خمسة) أسابيع، وزعت خلالها الوحدات التدريبية وبواقع (ץ) وحدات تدريبية في الأسبوع لكل مجموعة، وكان زمن الوحدة التدريبية لكلا الأسلوبين ( • (9) دقيقة . ب-1 التجارب الاستطلاعية : ب r-1-1 التجربـة الاستطلاعية الأولى (التجربـة الاستطلاعية للاختبـارات البدنيـة والمهاريـة

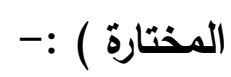

قام الباحث بإجراء التجربة الاسنطلاعية الأولى على مجموعة من اللاعبين البالغ عددهم

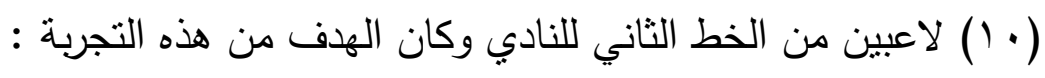
مدى وضوح الاختبار لعينة البحث وفههم له.

التأكد من التسلسل المنطقي لأداء الاختبارات المختارة. السيطرة على أزمنة إجراء الاختبارات البدنية والمهارية مدى صلاحية الأجهزة والأدوات المستخدمة في الاختبارات إمكانية فريق العمل *** من ناحية الكفاءة والعمل.

r-^-^ التجرية الاستطلاعية الثانية( التجربة الاستطلاعية للبرنامجين التدريبيين المقترحين $-:($

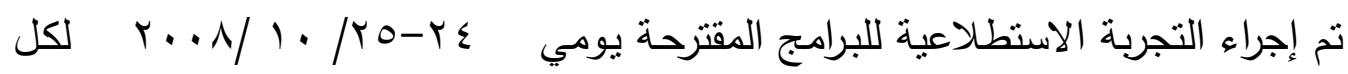

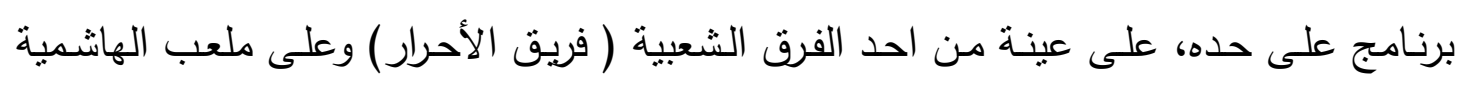
عدد كل منها (r () لاعباً، والغرض من عذه عذه التجربة الاستطلاعية : التأكد من مدى صلاحية استخدام الأساليب المقترحة كلاً على حدا التأكد من مدى ملائمة أوقات أجزاء الوحدات التدربيية وإمكانية تتفيذها . 


$$
\text { اختبار صلاحية وكفاية الأدوات المستخدمة في الوحدات التدريبية . }
$$

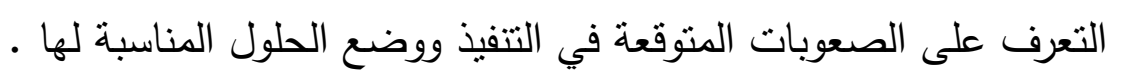
تدريب المدربين *على أزمنة التمارين والتكرارات.

وكان من نتائج هذه التجربة هو تكوين صورة واضحة لدى الباحث عن طبيعة العمل وكيفية التطبيق.

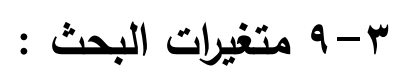

إذ أن من مميزات العدل التجريبي أن يقوم الباحث الكفء بفحص خططه التجريبية

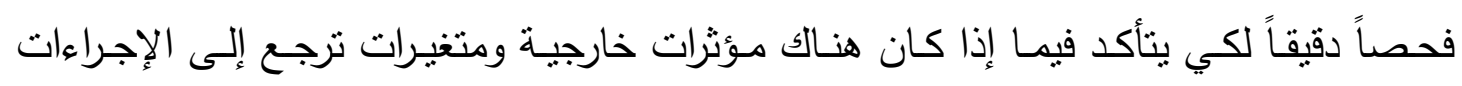

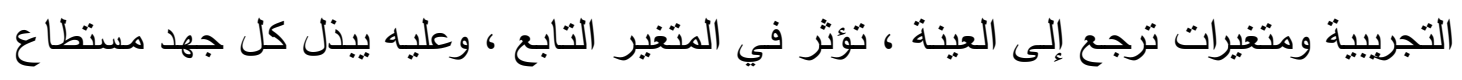

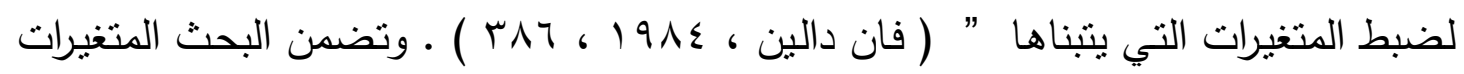
الآتية :-

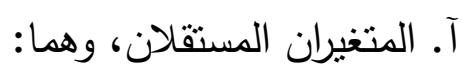

$$
\text { - أسلوب التمرين العشوائي. }
$$

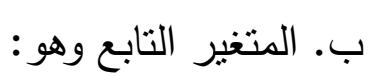

- مستوى الأداء المهاري للرجل غير المفضلة .

$$
\text { ج. المتغيرات غير التجريبية (الدخيلة): }
$$

ينبغي تحديد هذه المتغيرات والسيطرة عليها ، إذ قد تؤثر بطريقة أو بأخرى على سلامة المتغير

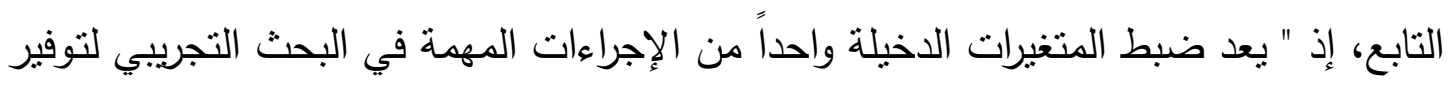

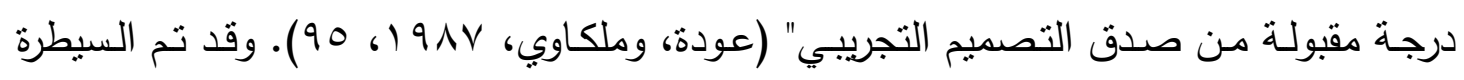

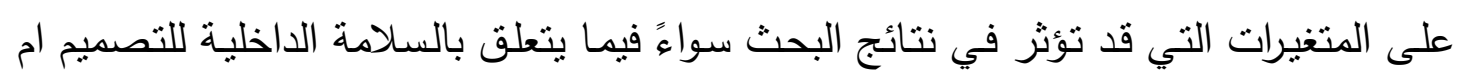

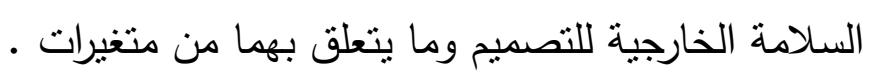




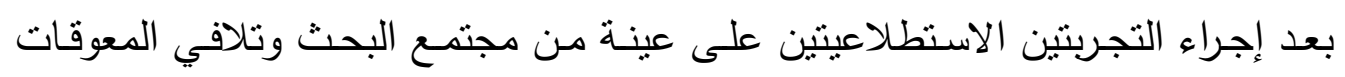

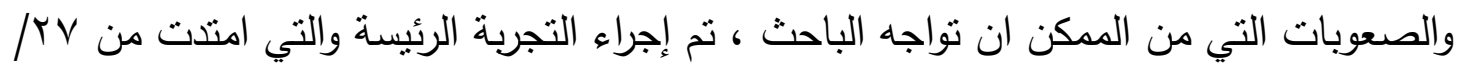

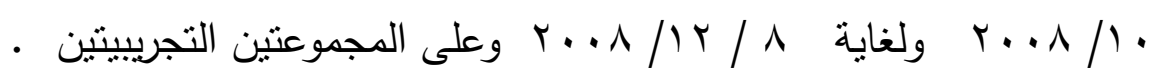
r- n - 11 الاختبارات القبلية والبعدية: ب-

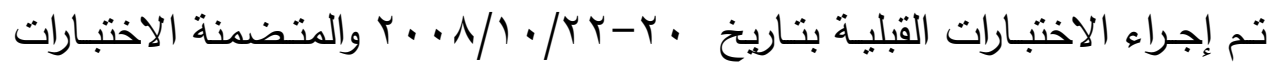
المهارية المختارة . r-11-r r- r الاختبارات البعدية :

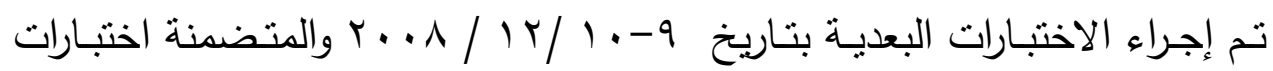
مهارية فقط.

\section{r-r الوسائل الإحصائية :}

استخدم الباحث البرنامج الإحصائي SPSS فضلاً عن استخدام الحاسبة اليدوية والتي تضمنت الوسائل الآتية : الوسط الحسابي .

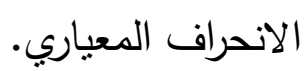
اختبار ( ت ) لوسطين حسابيين مرتبطين. اختبار ( ت ) لوسطين حسابيين غير مرتبطين.

( التكريتي ، والعبيدي، 1997 ، ( + (1 ) ). 
ع - 1 عرض نتائج الاختبارين القبلي والبعدي لبعض المهارات الأساسية لمجموعتي البحث

ومناقشتها:

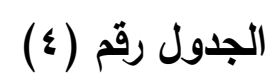

يبين الأوساط الحسابية والانحرافات المعيارية للاختبارين القبلي والبعدي وقيمة (تابل

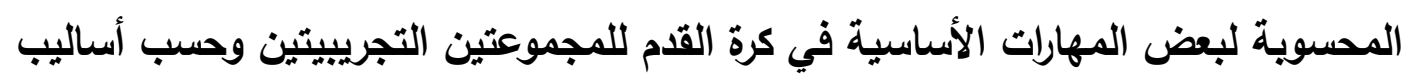
جدولة التمرين المستخدمة

\begin{tabular}{|c|c|c|c|c|c|c|c|c|c|}
\hline \multicolumn{3}{|c|}{ (أسلوب التمرين المتسلسل) التجريبية الثانية } & \multicolumn{3}{|c|}{ (أسلوب التمرين العشو ائي) } & \multirow{2}{*}{ لاختبار } & \multirow{2}{*}{ القياس } & \multirow{2}{*}{ الأساسية } & \multirow{2}{*}{$ت$} \\
\hline المصوية & $\varepsilon \pm$ & س س & المحسوية & $\varepsilon \pm$ & س س & & & & \\
\hline \multirow[t]{2}{*}{$\downarrow$} & $\cdot, \wedge \cdot 9$ & דוז, צ & \multirow{2}{*}{$\begin{array}{l}\hbar \\
|V . r u|\end{array}$} & $\cdot, q \leqslant r$ & $\varepsilon, .9$ & قبلي & \multirow{2}{*}{ درجة } & \multirow{2}{*}{ الإخماد } & \multirow{2}{*}{1} \\
\hline & $\cdot, \Delta \vee \varepsilon$ & $0, \lambda \mid \wedge$ & & 1.1 .4 & T.VYV & بعدي & & & \\
\hline \multirow{2}{*}{19.074} & תTr, & IV, TAV & \multirow{2}{*}{$9 . v \leq 0$} & . r rq. & $I V, O V \varepsilon$ & قبلي & \multirow{2}{*}{ ثانية } & \multirow{2}{*}{ الدحرجة } & \multirow{2}{*}{ r } \\
\hline & • & $1 v, 0 \vee q$ & & .017 & $\mid v .1 \ldots$ & بعدي & & & \\
\hline \multirow[t]{2}{*}{$\star \star$} & 1, rVo & $9,9.9$ & \multirow{2}{*}{$\begin{array}{l}\bar{n} \\
1.074\end{array}$} & $r, 11$. & זדז, 1. & قبلي & \multirow{2}{*}{ درجة } & \multirow{2}{*}{ التصبريرة } & \multirow{2}{*}{$r$} \\
\hline & $1,7 \vee \wedge$ & $11, V T V$ & & $1 . r V$ & זדז. ו & بعدي & & & \\
\hline \multirow[t]{2}{*}{$\star t$} & I, YAT & צדוד,0 & \multirow{2}{*}{$\begin{array}{l}\star \\
i . \wedge .\end{array}$} & 1,000 & $0, V Y V T$ & قبلي & \multirow{2}{*}{ درجة } & \multirow{2}{*}{ القريب } & \\
\hline & $1, \cdot 1$ & $V, V Y V$ & &. Orr & $1.0 \leq 0$ & بعدي & & & \\
\hline
\end{tabular}

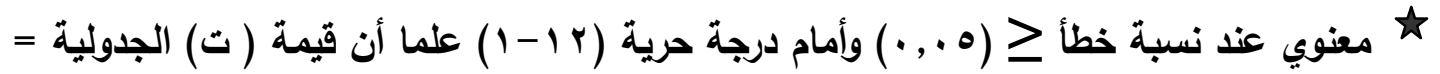
$(1, \Lambda \cdot)$

$$
\text { يتبين من الجدول رقم (ع) ما يأني :- }
$$

ا. وجود فروق ذات دلالة معنوية بين متوسطات درجات الاختبارين القبلي والبعدي في جميع

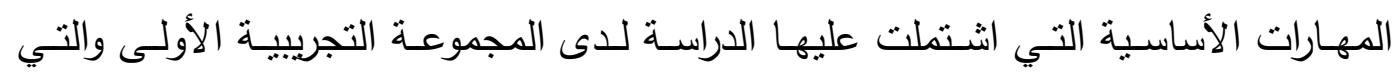

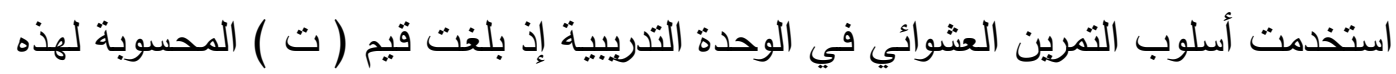

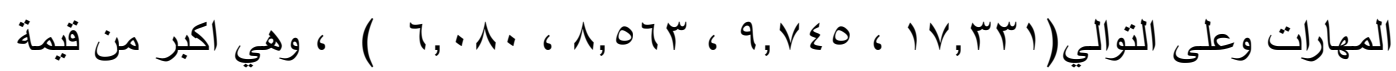




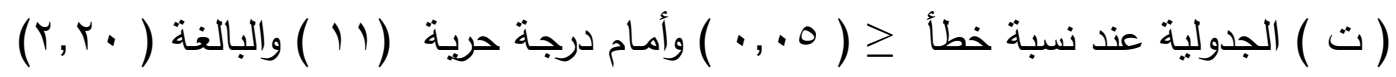

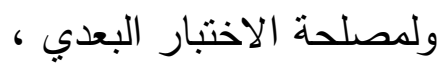

r. وجود فروق ذات دلالة معنوية بين متوسطات درجات الاختبارين القبلي والبعدي في جميع

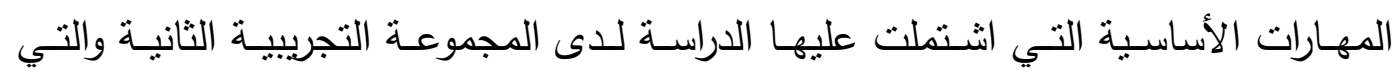

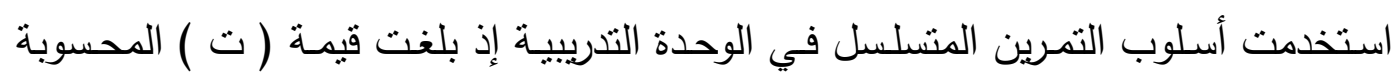

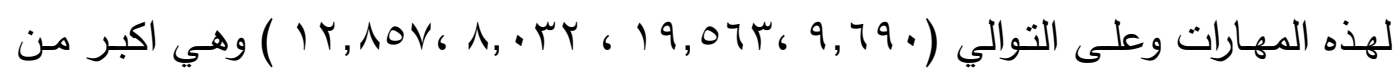

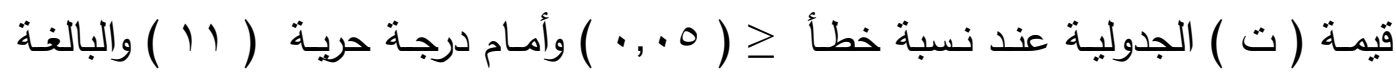

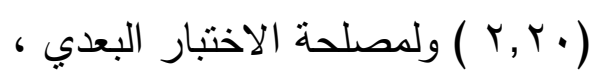

ويعزو الباحث هذه الفروق إلى فاعلية استخدام أسلوبي التمرينين المستخدمين في البحث

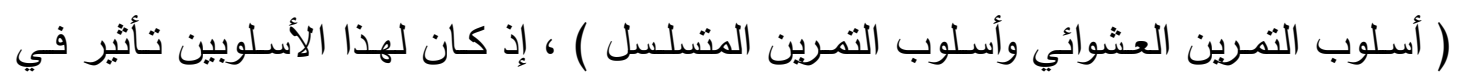

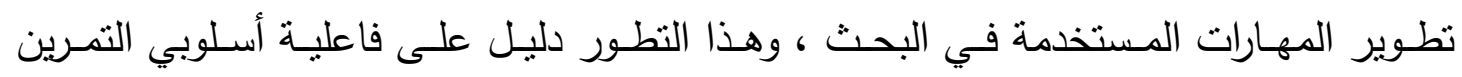

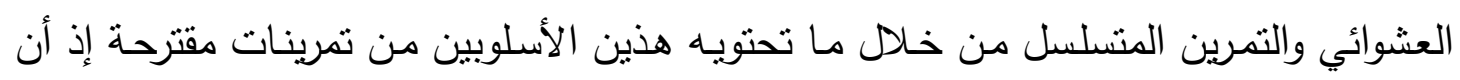

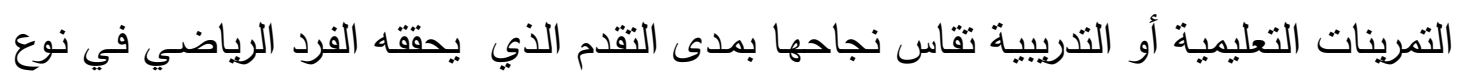

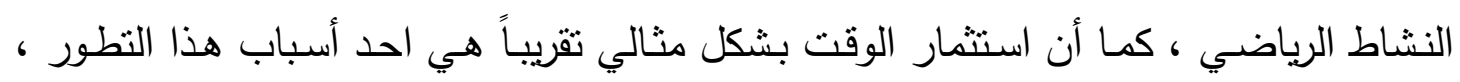

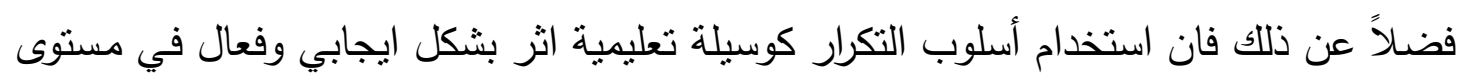

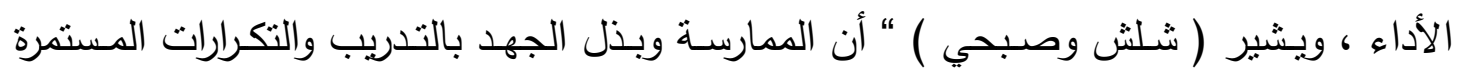
ضرورية في عملية التعلم ، والتدريب عامل مساعد وضروري في عملية تفاعل الفرد مع المهارة

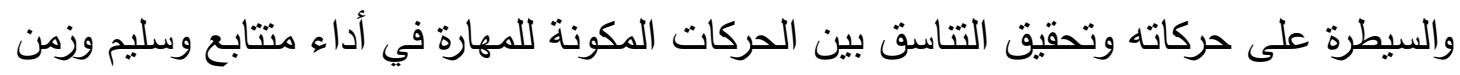

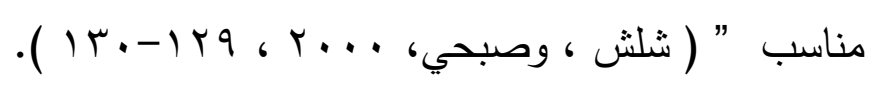

فالتكرار المعزز يساعد اللاعب على إتقان الحركات النوعية الني تمثل في مجموعها

المهارة المطلوب تعلمها ، وتحقيق التناسق بين هذه الحركات ، ويذكر ( Schmidt\&

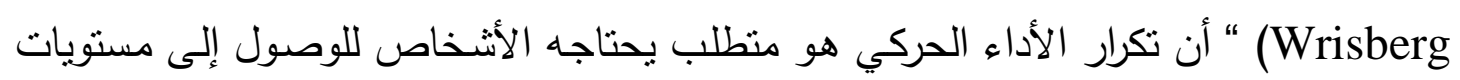
عالية من التعلم الحركي " ( 2000.21 . Schmidt\& Wrisberg ).

ع - r عرض ومناقشة نتـائج الاختبـارات البعديـة لمجمـوعتي البحـث في بعض المهارات الأساسية :

(0) - (الجدول رقم

110 
يبين الأوساط الحسابية والانحرافات المعيارية وقيمة ( ت ) المحسوية للاختبارات البعدية لبعض المهارات الأساسية في كرة القدم ولمجموعتي البحث

\begin{tabular}{|c|c|c|c|c|c|}
\hline \multirow{2}{*}{ قيمة (ت) } & \multicolumn{2}{|c|}{ مجموعة التمرين } & \multicolumn{2}{|c|}{ مجموعة التمرين العشوائي } & \\
\hline & $\varepsilon \pm$ & س س & $\varepsilon \pm$ & س & \\
\hline$\star_{r, 1 \leqslant Y}$ & $\cdot, \wedge \vee \varepsilon$ & $0, \wedge \backslash \wedge$ & $1,1 \cdot r$ & $7, V Y V$ & الإخمـاد \\
\hline$\hbar \varepsilon, \ldots \varepsilon$ & $\cdot, r \mu q$ & $1 \mathrm{~V}, 0 \mathrm{Vq}$ & $\cdot, M 17$ & $1 v, 1 \ldots$ & الاحرجـة \\
\hline 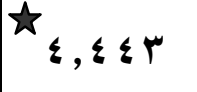 & $1,7 \vee \wedge$ & $11, V Y V$ & $1, \cdot T V$ & 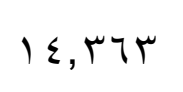 & التمريرة القصيرة \\
\hline${ }^{t} r, r \wedge \Lambda$ & $1, \cdot 1 \cdot$ & $V, V Y V$ & $\cdot$, OYY & $1,0 \leq 0$ & التهايف القريب \\
\hline
\end{tabular}

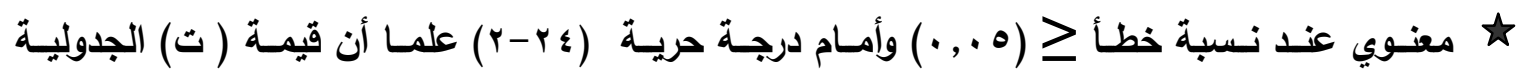

$$
r, \cdot V=
$$

من الجدول رقم ( 0 ) يتبين وجود فروق ذات دلالة معنويـة في نتائج الاختبار البعدي بين المجموعتين التجريبيتين وفي جميع المهارات المختارة في البحث ولصالح المجموعة التجريبية

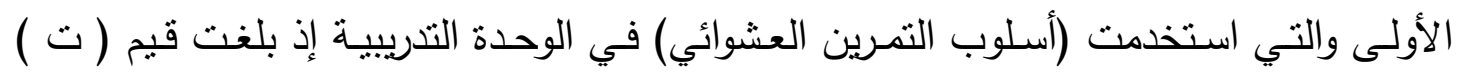

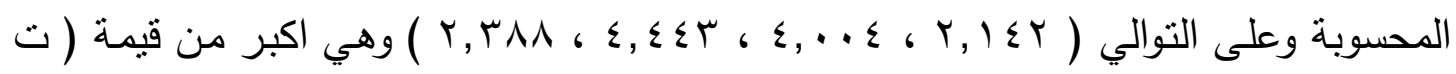

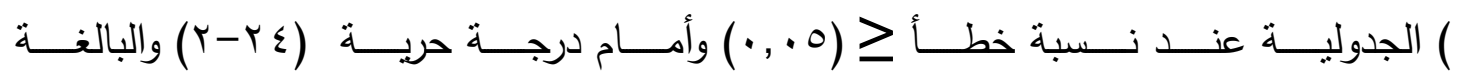

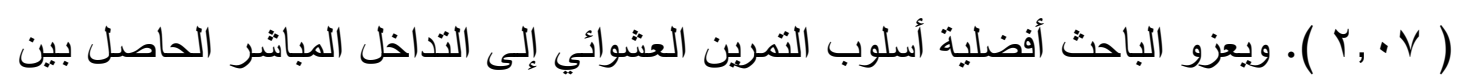

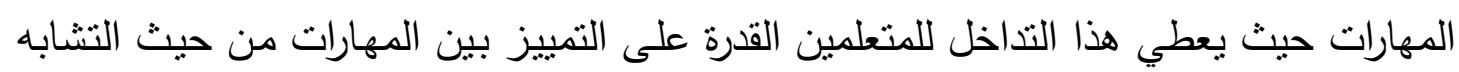

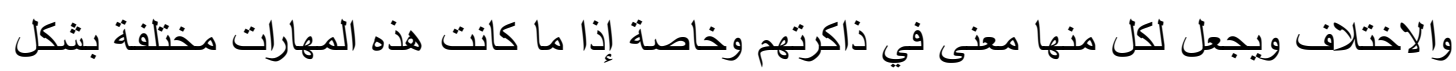

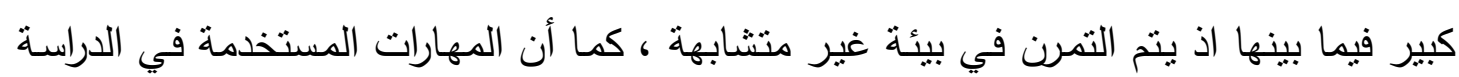

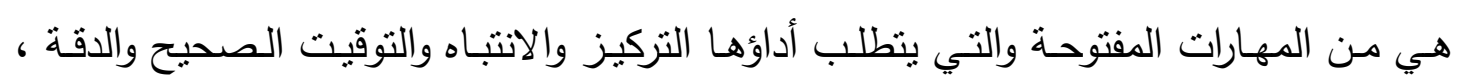

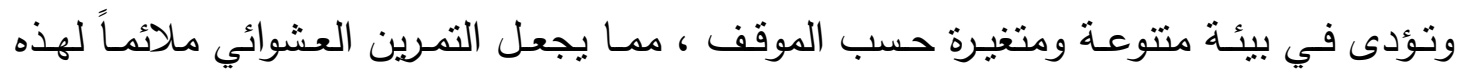

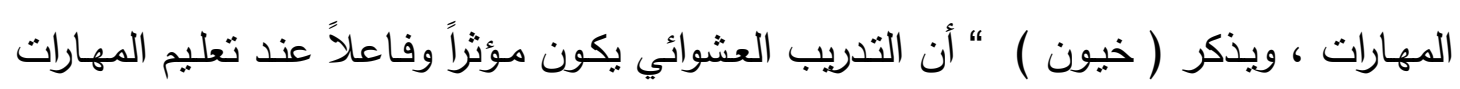

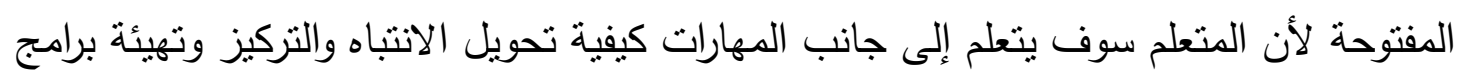

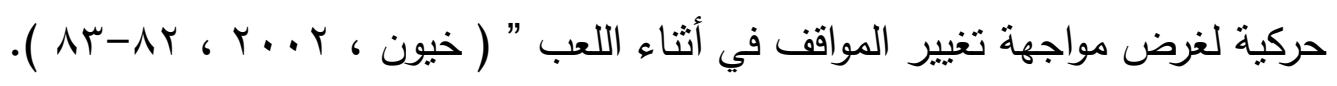




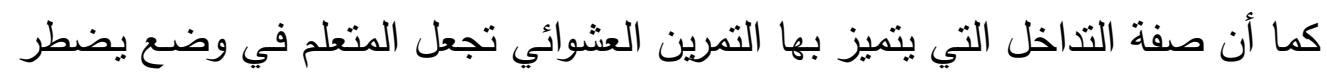

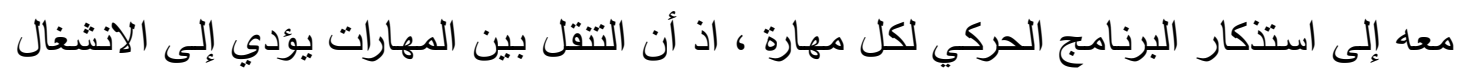

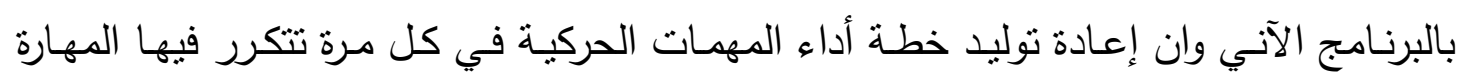

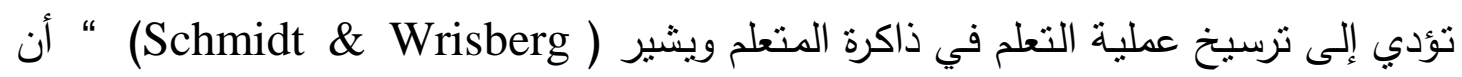
الأفراد في التمرين العشوائي حين يحين الوقت بالنسبة لهم للقيام بالمهمة ( أ ) مرة أخرى يتعين

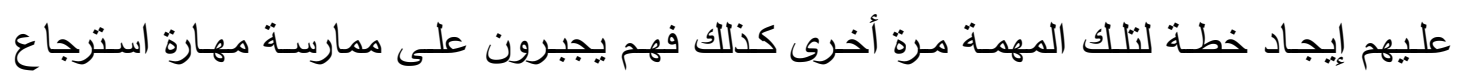
Schmidt\& )

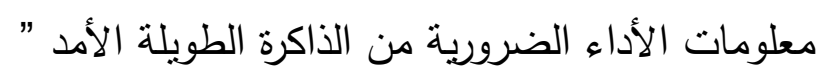

.( Wrisberg . 2000. 236

كما أن أسلوب التمرين العشوائي يوفر للمتعلم فرصة الربط بين المهارات الأربعة خله

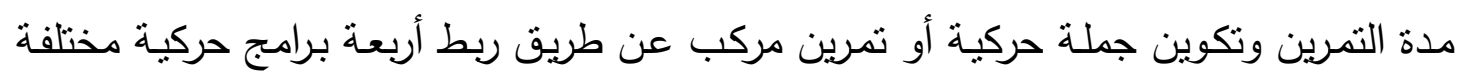

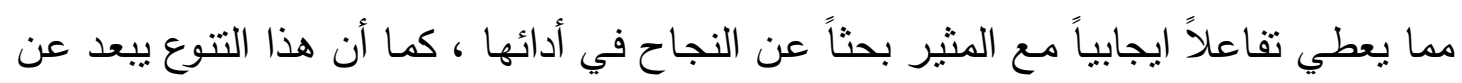

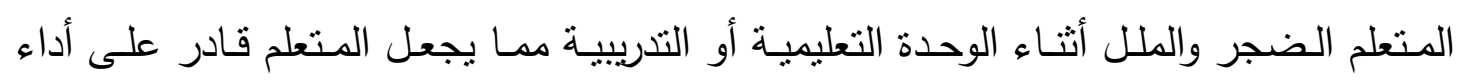

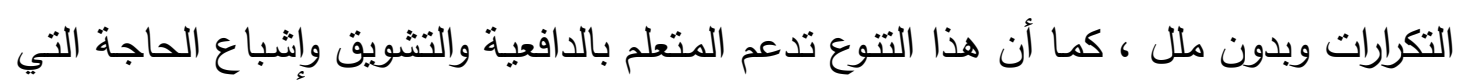

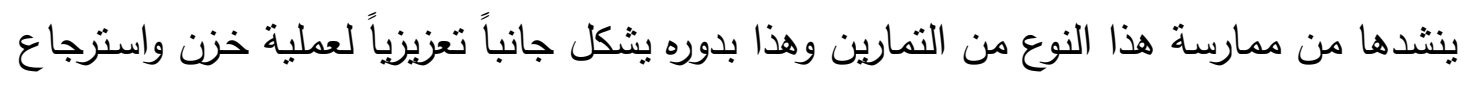

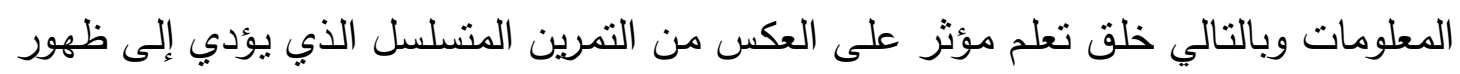

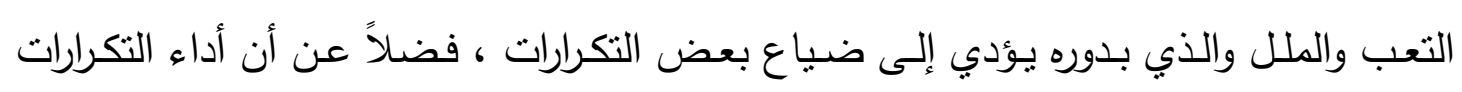

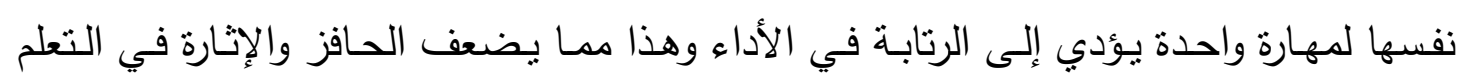

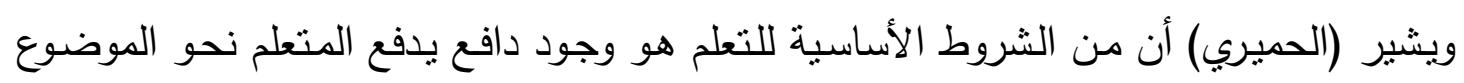

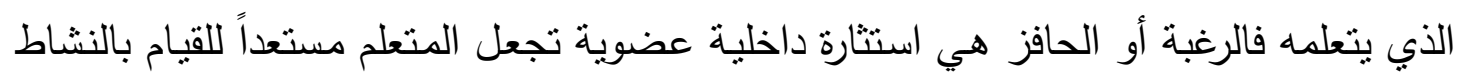
دون الإحساس بالضيق أو التوتر

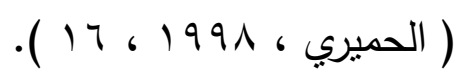

ويضيف ( عثمان ) " بأن العطلية التعليمية تتطلب اشتراك المتعلم بايجابية كما أنها تتطلب وجود دافع للنطور

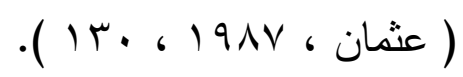


1- كان لأسلوبي جدولة التمرين (العشوائي ، والمتسلسل ) تأثثير ايجابي في تطوير الأداء المهاري للرجل غير المفضلة للاعبي كرة القدم.

ץ- إن أسلوب جدولة التمرين العشوائي كان الأفضل من أسلوب جدولة التمرين المنسلسل في

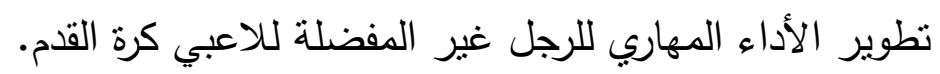

ه-r التوصيات:

ا. التأكيد على استخدام أسلوب جدولة التمرين العشوائي في تطوير الأداء المهاري للرجل غير المفضلة لدى للاعبي كرة القدم. r. أجراء بحوث مشابهة لمعرفة تأثير أساليب أخرى من جدولة التمرين على تطوير الأداء المهاري للرجل غير المفضلة للاعبي كرة القدم.

\section{المصادر العربية والأجنبية}

1. الاركي، عبد المعين صبحي خالد (99V (1): “أثر استخدام بعض الأجهزة والأدوات

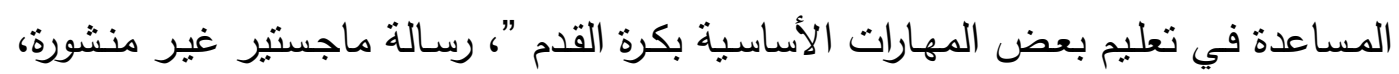

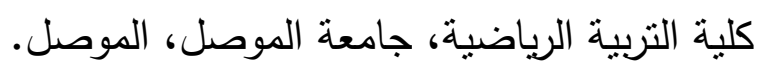
r. إسماعيل ، ثامر محسن وآخران ( 1991 ) ) “ الاختبار والتحليل بكرة القدم “ مطبعة جامعة الموصل ، الموصل.

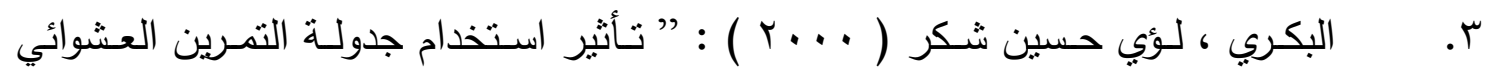

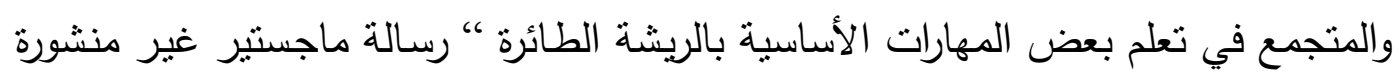

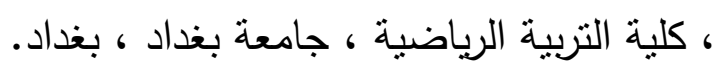

ـ. التكريتي ، وديع ياسين ، والعبيدي ، حسن محمد عبد (997 ()): التطبيقات الإحصائية

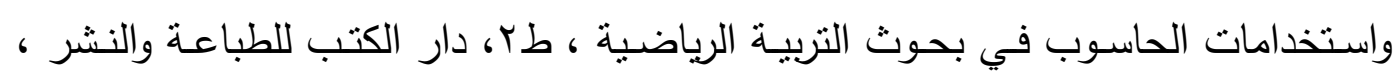
الموصل

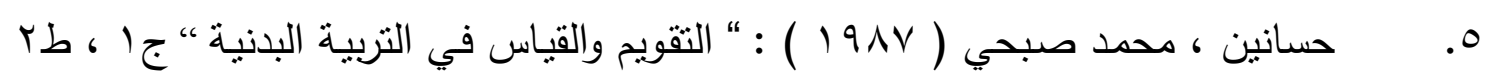
، دار الفكر العربي ، القاهرة

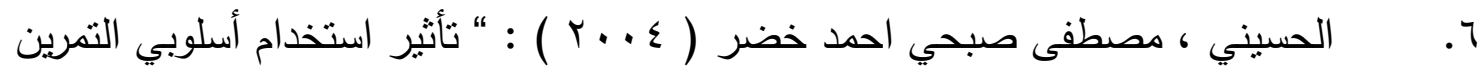

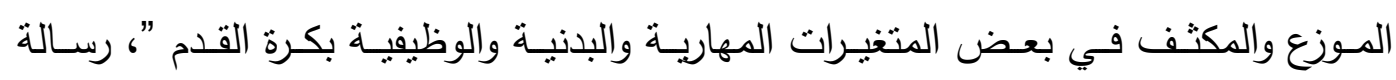
ماجستير غير منشورة ، كلية التربية الرياضية ، جامعة بغداد . V. حمـاد ، مفتي إبراهيم ( 1991 ) : “ التدريب الرياضـي الحديث ” ، ط1 ، دار الفكر

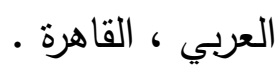


^. الحميـري ، ميسر مصطفى إسـماعيل ( 1991 ) : “ تتأثير برنـامج تمهيدي- تعليمي باستخدام أسـلوبي التمـرين المكثف والمـوزع في اكتساب بعض مهـارات التنس المنفصلة والاحتفاظ بها ، رسالة ماجستير غير منشورة ، كلية التربية الرياضية ، جامعة بغداد .

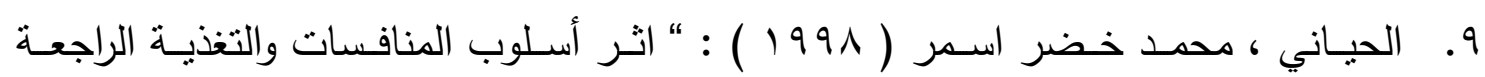
المقارنـة في الرضـا الحركي والتحصيل بكرة القدم ،، أطروحة دكتوراه غير منشورة ، كلية التربية الرياضية ، جامعة الموصل

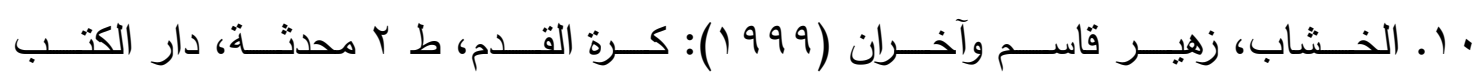
للطباعة والنشر ، جامعة الموصل، الموصل.

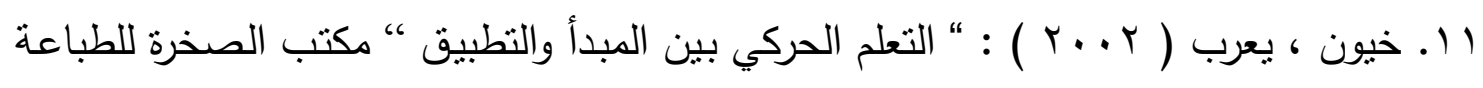

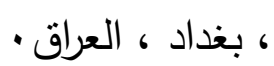

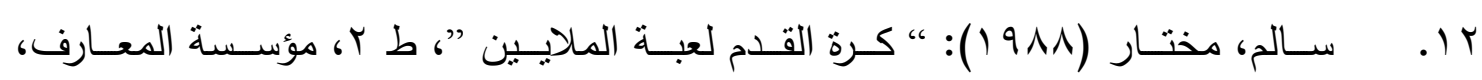
بيروت، لبنان.

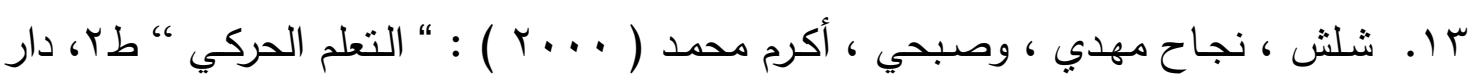
الكتب للطباعة والنشر ، جامعة الموصل ، الموصل .

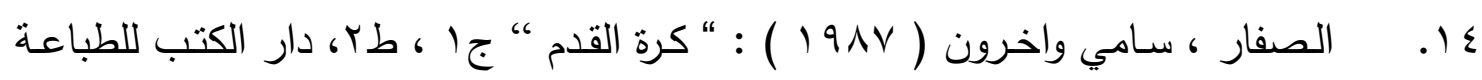
والنشر ، جامعة الموصل، الموصل.

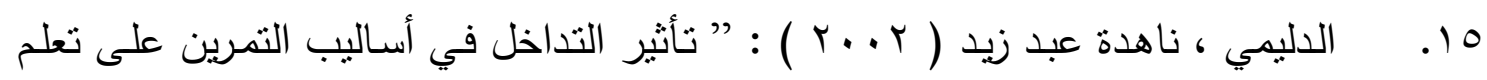
وتطـور مستوى أداء مهارتي الإرسـال الساحق والضرب الساحق بالـكرة الطـائرة ،“رسـالة ماجستير غير منشورة ، كلية التربية الرياضية ، جامعة بغداد، بغداد.

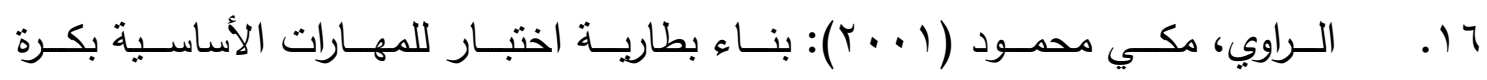
القدم للاعبي شباب محافظ نينوى، أطروحة دكتوراه غير منشورة، كلية التربية الرباضية، جامعة الموصل، الموصل. IV . عبد الجبار ، قيس ناجي ، وبسطويسي ، بسطويسي احمد ( I A ) ) : " الاختبارات ومبادئ الإحصاء في المجال الرياضي ،" مطبعة التعليم العالي ، بغداد.

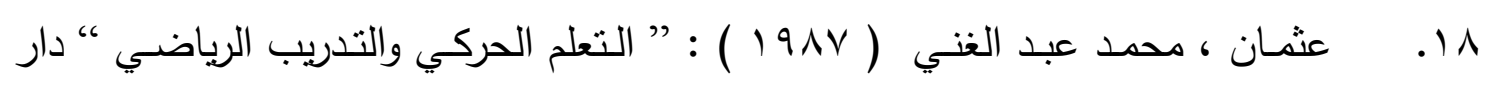
القلم ، الكوبت

9 1. علاوي ، محمد حسن ، وراتب ، أسامة كامل ( 1999 ) : “ البحث العلمي في التربية الرياضية وعلم النفس الرياضي ، طن ، دار الفكر العربي ، القاهرة . 


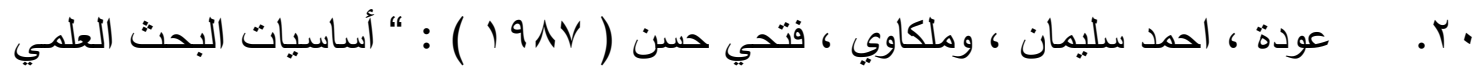

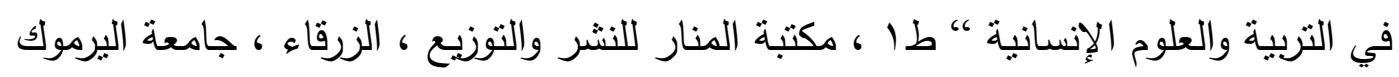

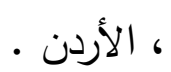

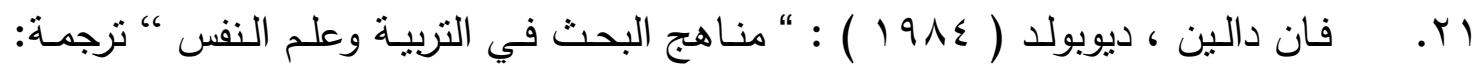
محمد نبيل نوفل واخرون ، طب ، مكتبة الانجلو المصرية ، القاهرة .

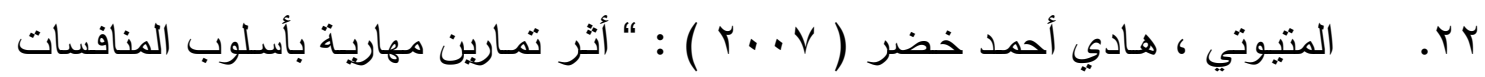
على تطوير بعض المهارات الأساسية للرجل غير المفضلة للاعبين الناثـئين بكرة القدم

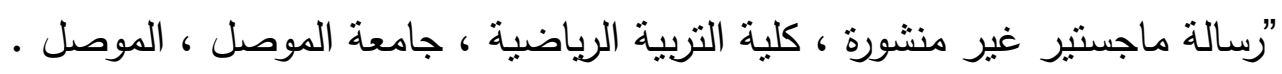

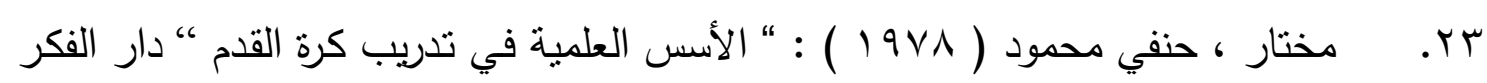
العربي ، القاهرة

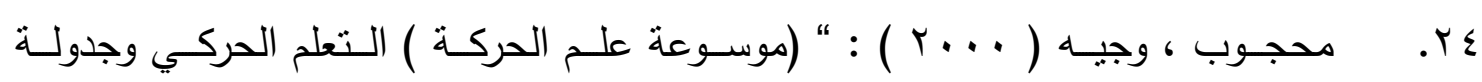

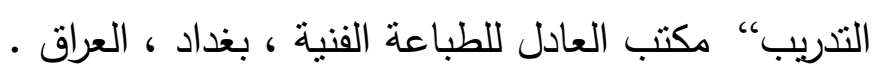

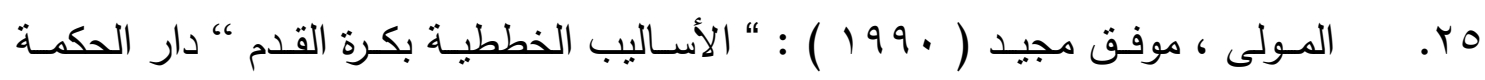

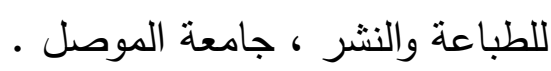

26. Herbert,Landin \& Solman (1996) : “ practice schedule effects on performance and learning of low and high skills student " Research Quarterly vo1., Burgess Publishing Company, U.S.A.

27. Gambeta, V.( 1984) "New studies in Athletice”,. Academic press, New York

28. Schmidt,A.Richard (1982): “ Theory of Discrete motor of skill learning " Research Quarterly. Human Kinetics Book, Champaign, Illinois

29. Schmidt,A.Richard (1991):“ Motor learning and performance ” Human kinetics Book, Champaign, IIIinois.

30. Schmidt,A.Richard \& Lee, D.Timothy (1999) : "Motor control and learning " 3ed Edition ,Human kinetics publishers, Champaign.

31. ) Schmidt, A. Richard \& Wrisberg Craig (2000) : “ Motor learning and performance " (2ed ,edition) Human kinetics publishers, Champaign

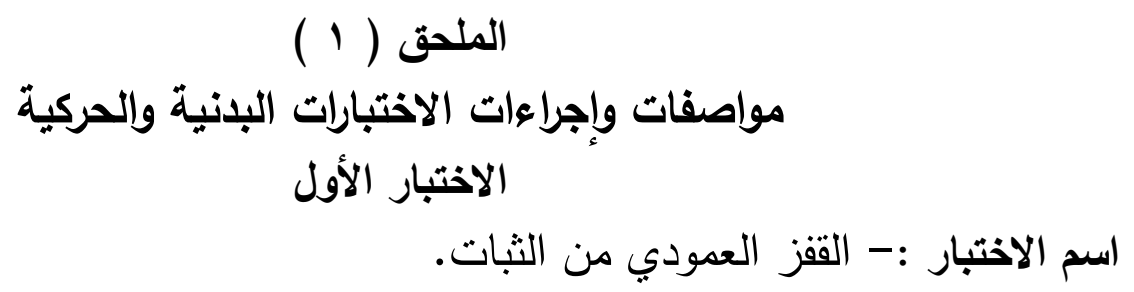


الهُف من الاختبار :- قياس القوة الانفجارية لعضلات الأطراف السفلى.

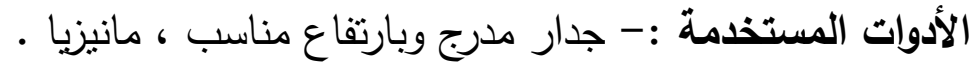

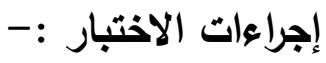

- يقف المختبر بحيث يواجه الجدار بأحد كتفيه ، بعد غمس يده في المانيزيا.

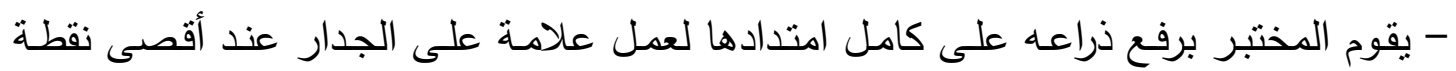

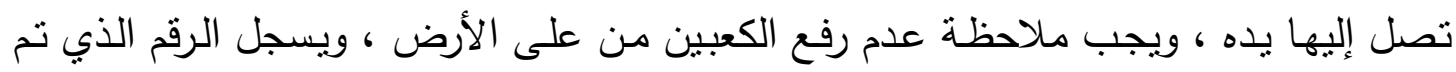

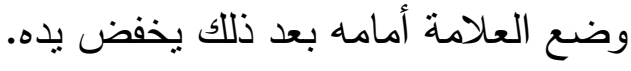

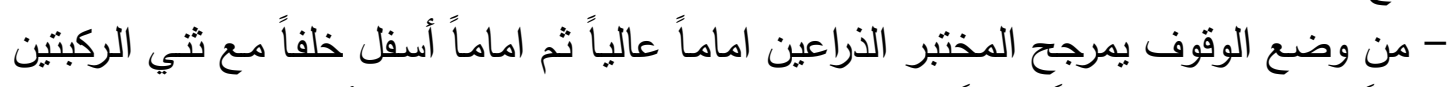

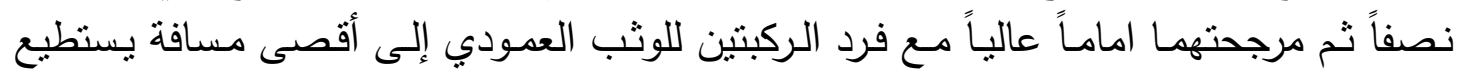

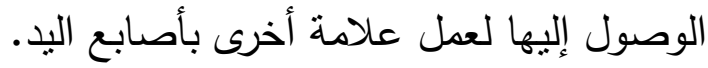
طريقة التسجيل :-

- يعطى المختبر محاولتين تسجل له افضلهمها.

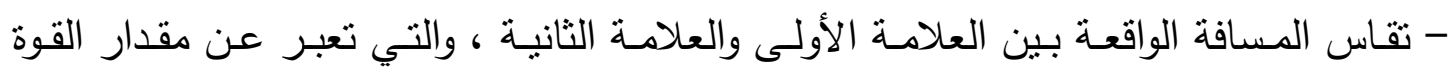

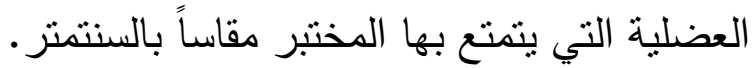

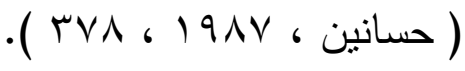

$$
\begin{aligned}
& \text { الاختبار الثاني } \\
& \text { اسم الاختبار :- الركض بين الثواخص لمسافة Vم . }
\end{aligned}
$$

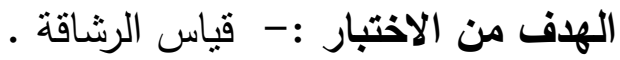

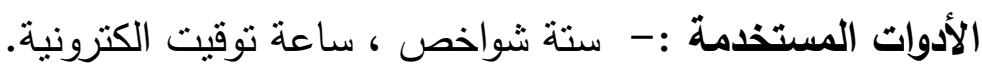

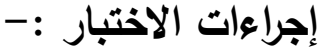

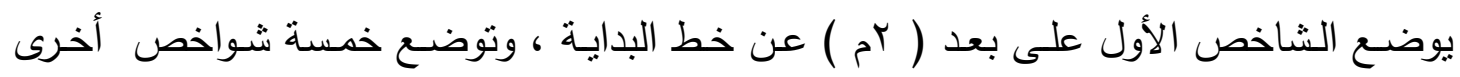

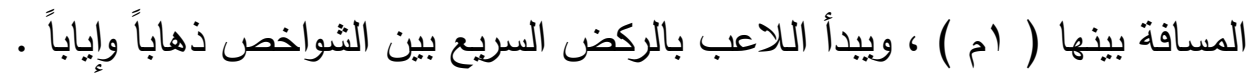

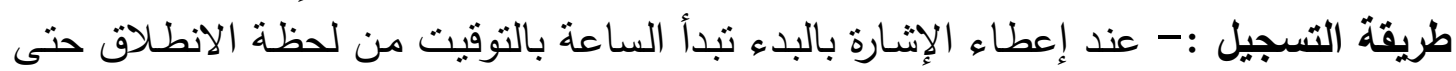

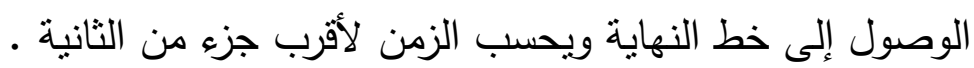

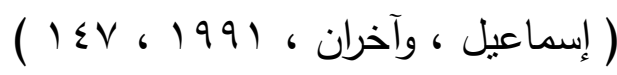

\section{الاختبار الثالث}

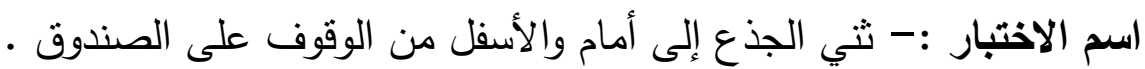

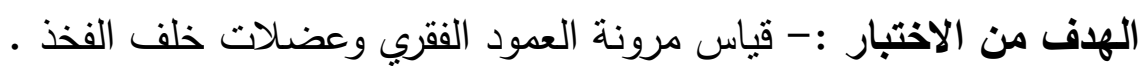

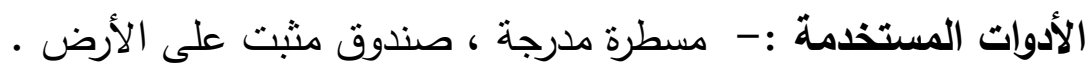

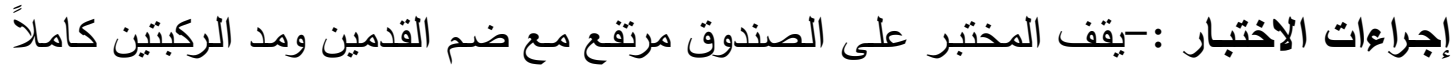

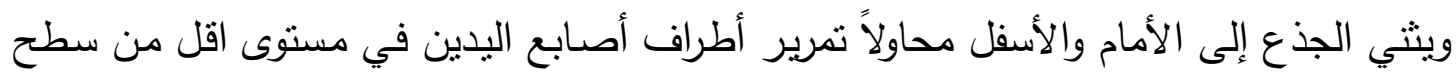

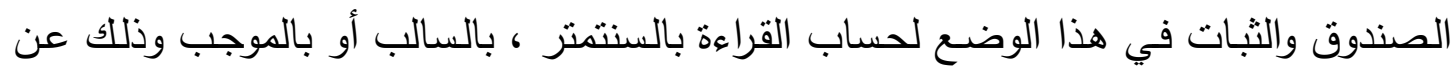
مستوى سطح الصندوق.

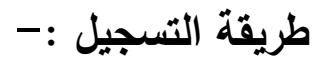




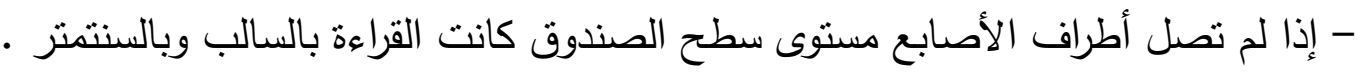

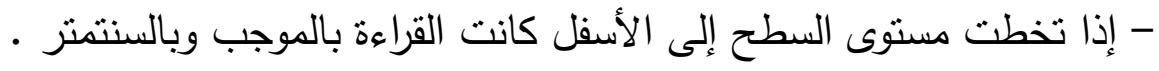

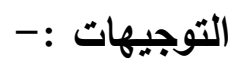

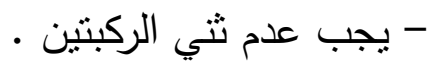

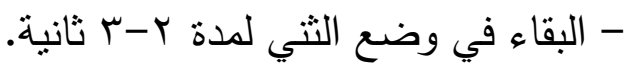

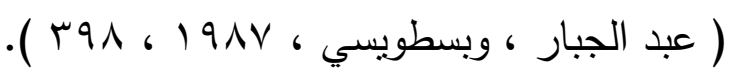

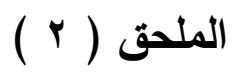 \\ مواصفات واجراءات الاختبارات المهارية \\ الاختبار الأول}

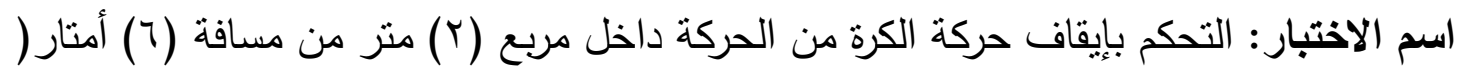
الإخماد ) (الإنيار:

الهلف من الاختبار: الإخماد (التحكم بإيقاف حركة الكرة).

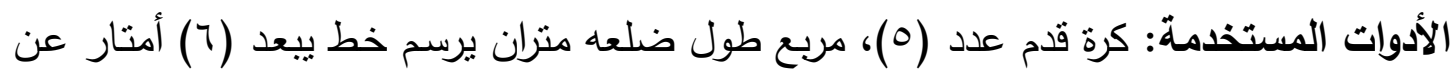
وصف الأداء:

- يقف اللاعب خلف منطقة الاختبار المحددة، يقوم المختبر برمي الكرة عالياً للاعب الذي الذي الكاري

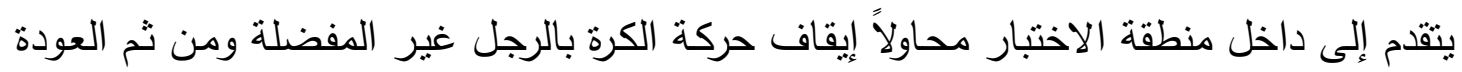

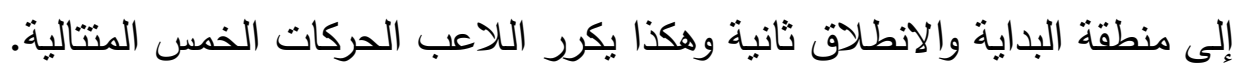
- يجب إيقاف حركة الكرة ضمن المنطقة المحددة للاختبار .

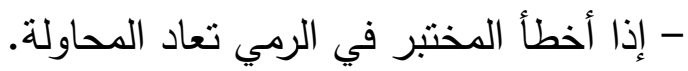
- لا تحتسب المحاولة صحيحة في الحالات الدات الآتية: ا إ إذا لم ينجح اللاعب في إيقاف حركة الكرة.

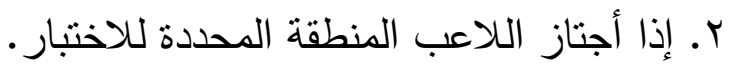
r. إذا لمست الكرة الذراع في أثناء إيقاف حركتها.

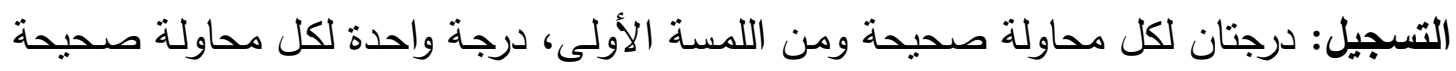

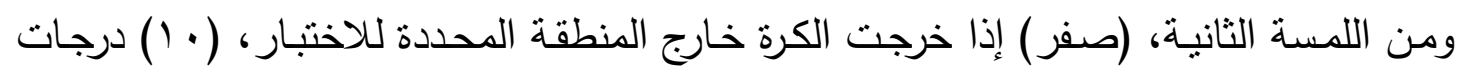
مجموع المحاولات الخمسة ينفة الاختبار بالرجل غير المفضلة.

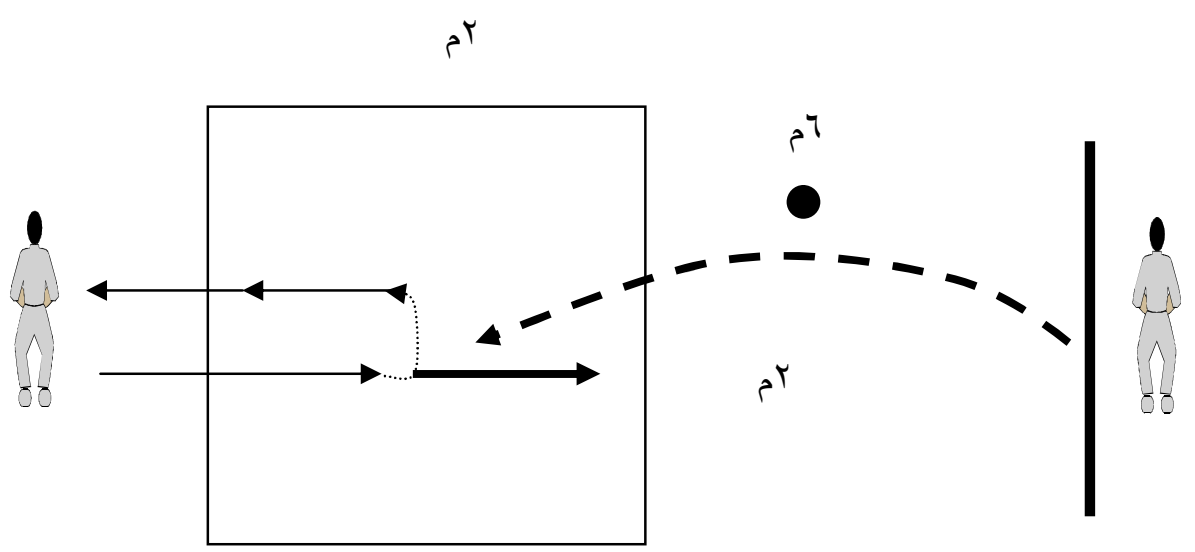




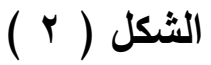

يوضح اختبار التحكم بإيقاف حركة الكرة من الحركة داخل مريع (ץ) متر

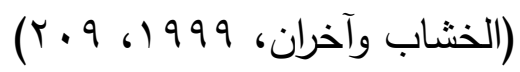

الاختبار الثاني

اسم الاختبار: اختبار الجري المتعرج بالكرة بين (0) شواخص.

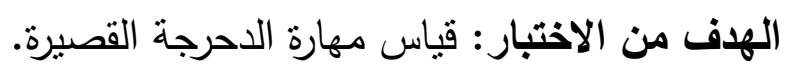

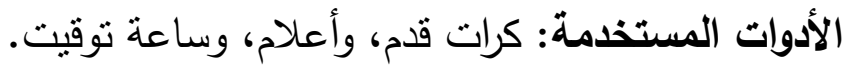

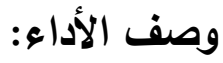

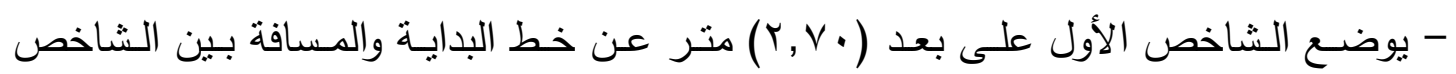

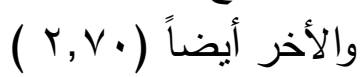

- يقف اللاعب ومعه الكرة خلف خط البداية وعندما تعطى إثنارة البدء يقوم اللاعب بدحرجة الكرة بالرجل غير المفضلة بين الثواخص ذهاباً وإياباً. - تعطى لكل لاعب محاولنتين متتاليتين.

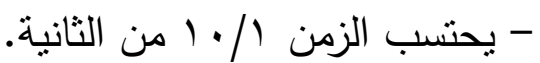

- درجة اللاعب هي متوسط الزمن الكلي الذي يستغرقه اللاعب في أداء المحاولتين. (Gambeta: 1984, 4)

الاختبار الثالث

اسم الاختبار: دقة التمريرة القصيرة.

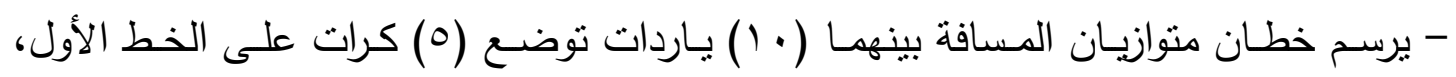

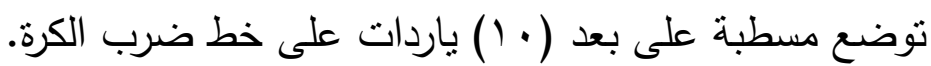

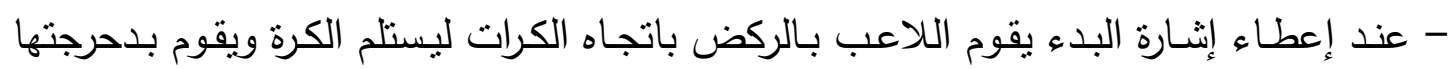

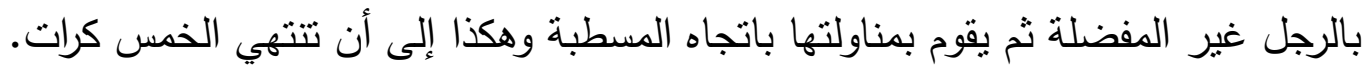

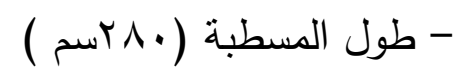
- تعطى لكل لاعب محاولتين.

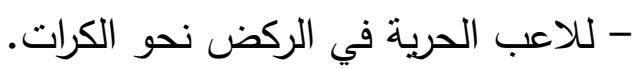
الهلف من الاختبار : قياس دقة التمريرة القصيرة.

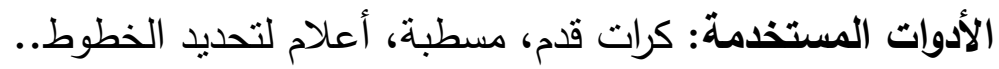

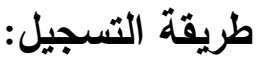

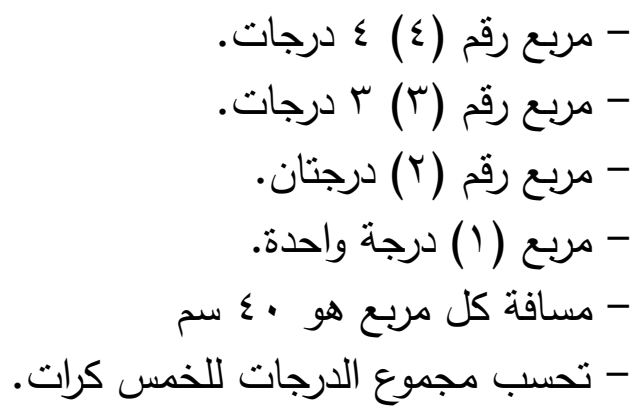




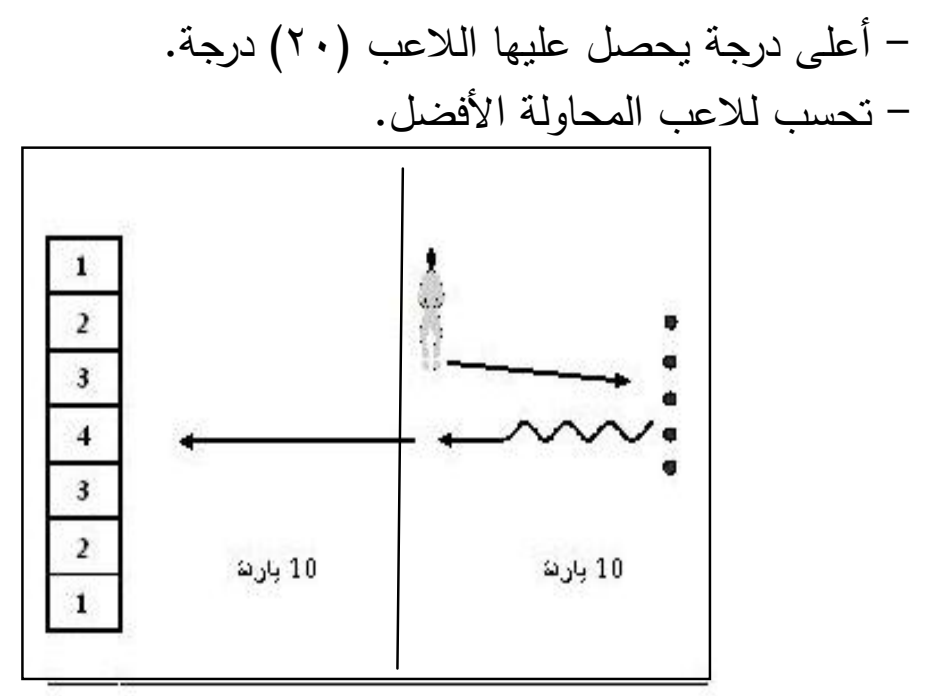

يوضح اختبار دقة التمريرة القصيرة

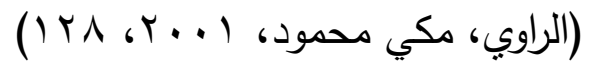

اختبار الرابع

اسم الاختبار: التهديف القريب.

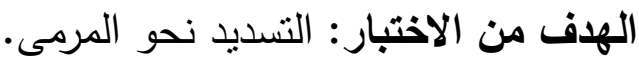

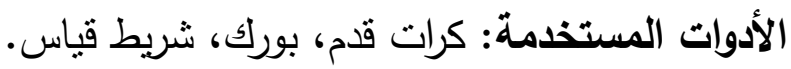

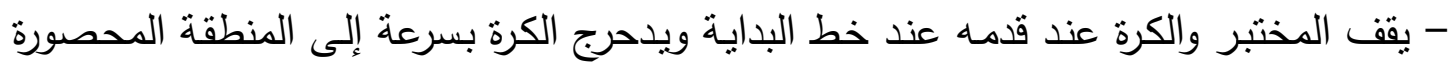

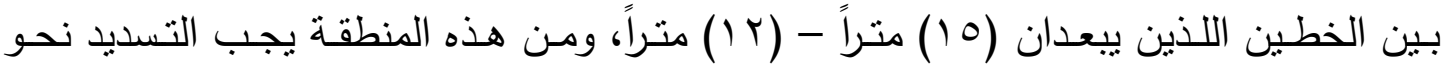
المرمى، ينفذ اللاعب (• (1) تسديدات بالرجل غير المفضلة. طريقة التسجيل: - تحسب التسديدة صحيحة عندما تدخل الكرة المرمى بين القائمين وتحت

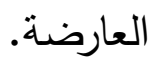


الثكل (๕)

يوضح اختبار التهايف القريب

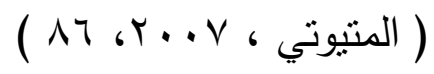

